\title{
SISTEMA AGROINDUSTRIAL DO LEITE: CUSTOS DE TRANSFERÊNCIA E PREÇOS LOCAIS
}

\author{
GuSTAVO FISCHER SBRISSIA
}

\begin{abstract}
Dissertação apresentada à Escola Superior de Agricultura "Luiz de Queiroz", da Universidade de São Paulo, para obtenção do título de Mestre em Ciências, Área de Concentração: Economia Aplicada.
\end{abstract}

P I R A C I C A B A

Estado de São Paulo - Brasil

Fevereiro - 2005 


\title{
SISTEMA AGROINDUSTRIAL DO LEITE: CUSTOS DE TRANSFERÊNCIA E PREÇOS LOCAIS
}

\author{
GuStavo Fischer SBRISSIA \\ Engenheiro Agrônomo
}

Orientador: Prof. Dr. GERALDO SANT'ANA DE CAMARGO BARROS

\begin{abstract}
Dissertação apresentada à Escola Superior de Agricultura "Luiz de Queiroz”, da Universidade de São Paulo, para obtenção do título de Mestre em Ciências, Área de Concentração: Economia Aplicada.
\end{abstract}

P I R A C I C A B A

Estado de São Paulo - Brasil

Fevereiro - 2005 
Dados Internacionais de Catalogação na Publicação (CIP) DIVISÃO DE BIBLIOTECA E DOCUMENTAÇÃO - ESALQ/USP

Sbrissia, Gustavo Fischer

Sistema agroindustrial do leite: custos de transferência e preços locais / Gustavo

Fischer Sbrissia. - - Piracicaba, 2005.

$58 \mathrm{p}$.

Dissertação (Mestrado) - - Escola Superior de Agricultura Luiz de Queiroz, 2005.

Bibliografia.

1. Indústria agrícola 2. Leite - Produção 3. Preço I. Título

CDD 338.1771

"Permitida a cópia total ou parcial deste documento, desde que citada a fonte - O autor" 


\section{Ofereço}

Aos meus pais, Luiz Carlos e Ursula

pelo apoio incondicional e confiança

em todos os momentos

\section{Dedico}

A meus irmãos André e Larissa, com o apoio

e incentivo, consegui atingir esse objetivo 


\section{AGRADECIMENTOS}

Sou grato a DEUS.

Meu orientador, Prof. Dr. Geraldo Sant'Ana de Camargo Barros, pela paciência e orientação sempre oportuna.

Aos professores Dr. José Roberto Canziani e Dra. Vânia Guimarães, pelo apoio em todos os momentos dessa dissertação.

Ao professor Dr. Sérgio De Zen, pela colaboração e orientação pessoal e profissional.

A Andréia, com seu incentivo e confiança, consegui atingir este objetivo, espero retribuir todo o apoio com muito carinho e amor

Aos amigos César e Conchas (Alexandre Nunes) pelas enriquecedoras conversas e discussões. Aos companheiros, Mauro Osaki e Humberto. A toda a equipe de funcionários e estagiários do CEPEA, pelas horas de estudo, trabalho e descontração, em especial ao Toró (Leandro Ponchio) pela confiança e apoio.

A excelente equipe de trabalho, sempre disposta a superar qualquer obstáculo, Ana Paula, Ana Francisca, Camila (Smilinguida), Marcia (Okici), Juliana (Iena), Érica, Raquel (Mortal), Priscila (Alkaida), Danusa (Leão), Lot (Kulista) e Pedro (Gorgonzola). 


\section{SUMÁRIO}

Página

LISTA DE FIGURAS …...................................................................................... vii

LISTA DE TABELAS .................................................................................... vii

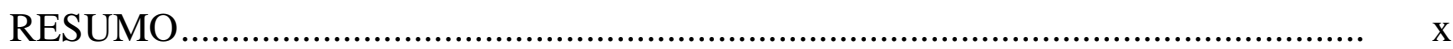

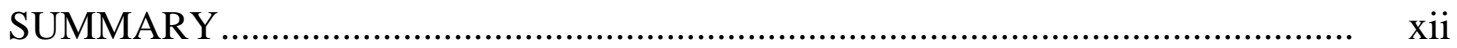

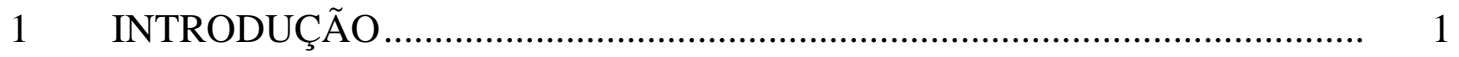

1.2 Diagnóstico do sistema agroindustrial do leite no Brasil e no Mundo.............. 3

1.3 Alterações nos polos geográficos de produção de leite ...................................... 8

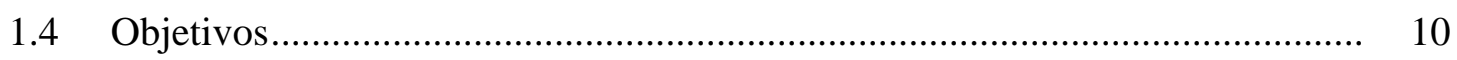

2 REVISÃO DE LITERATURA ….............................................................. 11

2.1 Formação dos preços ..................................................................................... 11

2.2 Pagamento por qualidade...................................................................... 14

$2.3 \quad$ Coleta de leite ......................................................................................... 16

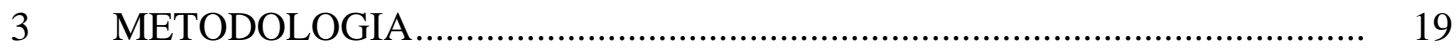

3.1 Caracterização da pesquisa e coleta de dados ................................................... 19

3.2 Custo de transferência e preços locais .............................................................. 20

3.3 Custo de transferência e preços locais: efeitos da falta de concorrência........... 26

3.3.1 Preços locais e distância .................................................................................... 26

3.3.2 Preços locais e tamanho de fornecedores ........................................................ 28

3.4 Funções de custo de transferência e preços locais............................................. 28

$4 \quad$ RESULTADOS E DISCUSSÃO................................................................ 31

4.1 Sistemas de pagamento e cobrança de frete .................................................... 31

4.2 Variação de preços e cobrança de frete ........................................................... 35

4.3 Preços do leite ao produtor: efeitos do tamanho................................................ 40 


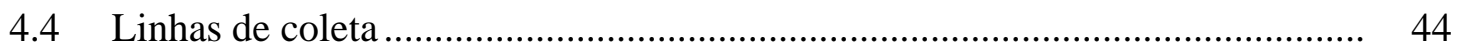

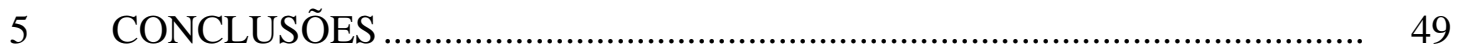

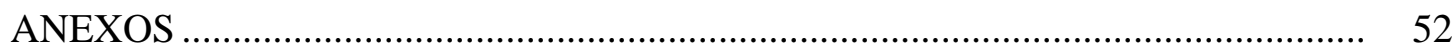

REFERÊNCIAS BIBLIOGRÁFICAS _............................................................... 56 


\section{LISTA DE FIGURAS}

Página

1 Distância e custo de transferência ......................................................................... 22

2 Superfícies de custo de transferência ....................................................................... 24

3 Superfícies de preços locais com produção dispersa............................................... 25

4 Representação percentual do pagamento por qualidade, volume e qualidade e volume em diferentes estados brasileiros ............................................................. 33

5 Representação percentual do pagamento por qualidade, volume e qualidade e volume na formação do preço do frete em diferentes estados brasileiros

6 Volume mensal coletado e preços médios ponderados pagos nas diferentes linhas de coleta

7 Variações percentuais entre os preços mínimos e máximos das diferentes linhas de coleta. 


\section{LISTA DE TABELAS}

Página

$1 \quad$ Maiores produtores de leite em 2002 ................................................................. 4

2 Mudanças ocorridas nas últimas décadas na Nova Zelândia ................................. 6

3 Comportamento das vendas internas de leite longa vida 1990/2002 .................. 9

4 Estados amostrados e suas respectivas participações na produção total de leite no Brasil e número de cooperativas pesquisadas .................................................. 32

5 Formas de pagamento aos produtores de leite (\%) em diferentes estados do Brasil

6 Contribuição do volume e quantidade coletada na formação do preço do frete (\%) em diferentes estados brasileiros

7 Valores médios e totais do volume de leite entregue e frete pago por 1.666 produtores de cinco cooperativas, 2003 .......................................................... 36

$8 \quad$ Resumo do primeiro quintil ......................................................................... 37

$9 \quad$ Resumo do segundo quintil .............................................................................. 37

10 Resumo do terceiro quintil ......................................................................... 38

11 Resumo do quarto quintil ........................................................................... 38

12 Dados referentes ao último quintil ................................................................ 39

13 Valores recebidos, volume de leite entregue e frete pago por 1.666 produtores de cinco cooperativas, 2003 …............................................................................ 40

14 Influência do volume individual e do número de produtores na linha no frete pago pelo produtor

15 Influência do volume individual e do número de produtores na linha no preço líquido recebido 
16 Influência do volume total da linha e do número de produtores no preço médio recebido pelos produtores, ponderado pelo volume individual 


\section{SISTEMA AGROINDUSTRIAL DO LEITE: CUSTOS DE TRANSFERÊNCIA E PREÇOS LOCAIS}

Autor: GUSTAVO FISCHER SBRISSIA

Orientador: Prof. Dr. GERALDO SANT'ANA DE CAMARGO BARROS

\section{RESUMO}

O presente trabalho estudou os sistemas de pagamento de leite no Brasil, nos seis principais estados produtores. Analisou e discutiu a diferenciação de preços do leite em decorrência do pagamento de bonificações por volume de 1666 produtores dentro de 62 diferentes linhas de coleta de 5 cooperativas. Cerca de $34 \%$ das cooperativas amostradas no Brasil pagam por volume e cerca de 55\% das cooperativas utilizam os critérios de volume e qualidade na remuneração dos produtores. Para o pagamento do frete, $58 \%$ das cooperativas cobram o frete somente pelo volume entregue, enquanto 23\% utilizam os critérios distância e volume no cálculo do frete e 19\% das cooperativas cobram o frete dos produtores pela distância percorrida. Na segunda etapa foram selecionadas cinco cooperativas que utilizavam somente o critério volume no pagamento do leite. O volume total captado no mês pela amostra foi de 4.300 .810 litros, em 62 linhas de coleta das cinco cooperativas. A média foi de 106 litros/dia por produtor, com um mínimo de 0,6 litros até um valor máximo de 3983 litros/dia para o maior produtor. O trabalho também analisou o frete pago por litro. A média da amostra foi de $\mathrm{R} \$$ 0,029/litro, com um pagamento variando desde nenhuma cobrança de frete até R \$ 0,070 por litro. O valor líquido por litro apresentou uma média de $\mathrm{R} \$ 0,373$, com um mínimo de R \$ 0,255 e um valor máximo de R\$ 0,541, variações de 112\%. Foi observado que o valor recebido pelo litro do leite aumenta significativamente com o aumento do volume. 
As constatações efetuadas permitem afirmar que o valor do frete cobrado aos produtores, como se poderia esperar, está vinculado positivamente ao tamanho da rota de coleta e ao número de produtores na rota e negativamente ao volume coletado de cada produtor. Essas mesmas variáveis influem também de acordo com a lógica econômica nos preços recebidos pelos produtores. Observou-se, todavia, que o volume produzido influenciava positivamente os preços recebidos também por outras vias que não seu impacto sobre o valor do frete. Essa é, fora de dúvida, uma forte evidência favorável à discriminação de preços contra os menores produtores, embora não seja uma prova cabal da ocorrência de tal fato. 


\title{
DAIRY VALUE CHAIN: TRANSFER COST AND LOCAL PRICES
}

\author{
Author: GUSTAVO FISCHER SBRISSIA \\ Adviser: Prof. Dr. GERALDO SANT`ANA DE CAMARGO BARROS
}

\section{SUMMARY}

This article aimed to study payment systems of milk in Brazil, in the six main producing states. It analyzed and discussed the different milk prices practiced due to the paying of bonus per volume, of 1,666 producers, among 62 different lines of collect of 5 cooperatives. Roughly 34\% of the studied cooperatives in Brazil pay per volume and around $55 \%$ of the cooperatives use the criteria of volume and quality to pay producers' income. For the freight payment, 58\% of the cooperatives charge the freight only based on the volume delivered, whereas $23 \%$ use the criteria of distance and volume in the figures and 19\% of the cooperatives charge producers the freight based on the distance run. On the second phase was chosen 5 cooperatives, which use only the criterion of volume to pay the milk. The amount of volume obtained in the month studied totaled 4,300,810 liters, in 63 lines of collect of 5 cooperatives. The average was 106 liters/day per producer, with the minimum of 0.6 liters up to a maximum value of 3,983 liters/day for the biggest producer. The study also analyzed the freight paid per liter. The average of the study was $\mathrm{R} \$ 0.029 /$ liter, with the payment ranging from no charge of freight up to $\mathrm{R} \$ 0.070$ per liter. The net value per liter showed an average of $\mathrm{R} \$ 0.373$, with the minimum of $\mathrm{R} \$ 0.255$ and a maximum price of $\mathrm{R} \$ 0.541$, variations of $112 \%$. It was observed that the value received per liter of milk significantly increases with the raise of volume. The conclusions obtained alow to state that the price of the 
freight charged on the producers, as It was expected, is linked positively to the length of the route of collect and to the number of producers in the route and negatively to the volume collected from each producer. These very variables affect also according to the economic logic of the prices received by producers. It was noticed, however, that the volume produced affected positively the prices received also by other vias that did not have any impact on the freight price. This is, without doubt, one strong evidence favorable to the discrimination of prices against minor producers, even thought it is not a real proof of such fact. 


\section{INTRODUÇÃO}

O sistema agroindustrial do leite vem passando por transformações sensíveis desde a desregulamentação do setor em 1991 e a abertura da economia ao comércio exterior. Diante desse quadro, produtores de leite, indústrias e cooperativas estão diante de um futuro incerto. Verifica-se um deslocamento geográfico dos pólos de produção, com novos estados e bacias leiteiras emergindo no cenário nacional e uma maior concentração de indústrias e cooperativas, através de aquisições e fusões.

Para Dornelas (2000), além dessas transformações, a mudança estrutural de coleta e transporte de leite, com aumento significativo do transporte granelizado e refrigerado iniciado em 1995, será determinante, incentivando progressivamente a modernização de práticas de manejo do rebanho e de conservação do leite. Qual será o formato das propriedades de leite nos próximos anos? De um lado, têm-se as propriedades familiares, apresentando tendência de serem mais flexíveis e se adaptarem melhor às mudanças no meio e circunstâncias sociais, já que a dependência quase que exclusiva da família reduz custos. De outro lado, pode-se argumentar que a economia de escala é especialmente crítica, devido à diluição dos custos fixos, sendo a expansão condição necessária para a sobrevivência. Freqüentemente, o tamanho da atividade tem sido associado também aos custos de transporte, com reflexos sobre os preços recebidos pelos produtores. Este é o objeto central deste estudo.

Tem se verificado nas principais empresas e cooperativas leiteiras um aumento da captação e redução do número de fornecedores, indicando ganhos em escala, e possivelmente, de produtividade e eficiência. O Brasil apresentou nos últimos anos um 
aumento no consumo per capita de leite e derivados. Houve popularização do leite em embalagem "longa-vida" decorrente de sua praticidade de seu consumo e de economias ligadas ao aumento da vida útil de prateleira e redução dos gastos com reposição e manutenção do produto em câmaras refrigeradas. O custo de transporte se reduz, sendo comum encontrar nos supermercados esse tipo de leite proveniente de diversos estados brasileiros, mudando a característica regional da produção e distribuição do leite pasteurizado até então prevalecente. Essa foi uma das significativas mudanças ocorrida no mercado de lácteos.

Primo (2001) acredita que o retardamento da modernização da pecuária leiteira, ocasionado pelo controle de preços exercido por mais de 40 anos, resultou na produção de matéria-prima de qualidade inferior, custos industriais mais altos e restrições às opções de produção. O leite de qualidade inferior não atendia às novas exigências do consumidor, ficando a indústria brasileira com limitada capacidade de competir em mercados internacionais. Este era o cenário vivido até o início dos anos noventa. A criação do Mercado Comum do Sul (MERCOSUL) em 1991, entre Argentina, Brasil, Paraguai e Uruguai, estabeleceu uma livre circulação de mercadorias entre os países, e junto com a liberação dos preços do leite, fez com despertasse o fator competitivo, buscando ganhos de produtividade e modernização.

Para Breda (2001), paralelamente a essas mudanças, e até por decorrência delas, verificaram-se outras alterações no setor leiteiro: o sistema cooperativo perdeu espaço para poucas empresas multinacionais que passaram a dominar o mercado; aumentou a concentração no mercado varejista e o poder de formação de preços das grandes redes de supermercado.

O Brasil está atravessando uma fase de alterações nas formas de remunerar o produtor. É verdade que o país não possui uma legislação sanitária exigente para o leite e o produtor pouco tem sido incentivado a produzir com qualidade. Com exceção de algumas empresas que já possuem pagamentos diferenciados por qualidade, ainda estão em fase de discussão novas formas de pagamento do leite. Para Barros et al. (2000) vem 
sendo utilizada, na grande maioria dos laticínios, a bonificação por volume: o produtor que entrega mais, recebe mais por unidade, independentemente da qualidade do produto. Se, por um lado, o maior volume não garante que o produto seja de melhor qualidade, por outro, permite uma maior segurança no planejamento da indústria e provavelmente reduções nos custos de coleta, o que, para as empresas, pode justificar o pagamento de preços mais atrativos para maiores volumes.

\subsection{Diagnóstico do sistema agroindustrial do leite no Brasil e no Mundo}

Segundo a Organização das Nações Unidas para Agricultura e Alimentação (FAO), em 2002 o comércio internacional de lácteos movimentou 26.895 bilhões de dólares, o que correspondeu a aproximadamente 73.546 bilhões de toneladas métricas em equivalente-leite A produção mundial de leite em 2002 foi de aproximadamente 599 bilhões de litros, como pode ser visto na Tabela 1 . O leite é produzido em praticamente todos os países do mundo e tem uma importância pelo seu valor na alimentação humana e na geração de emprego. Os 15 maiores produtores foram responsáveis por mais de 63\% da produção e o Brasil, com 3,8\% da produção mundial, ocupou a sexta posição nesta classificação. A produção nacional está bem acima de países considerados referências na produção mundial, como Nova Zelândia e Argentina. 
Tabela 1. Maiores produtores de leite em 2002 (bilhões de litros)

\begin{tabular}{lcrc}
\hline País & $\begin{array}{c}\text { Produção } \\
\text { (bilhões de litros) }\end{array}$ & $\%$ & Acumulado \\
\hline Índia & 85,00 & 14,20 & 14,20 \\
EUA & 77,02 & 12,87 & 27,06 \\
Rússia & 33,47 & 5,59 & 32,65 \\
Alemanha & 28,04 & 4,68 & 37,34 \\
França & 25,98 & 4,34 & 41,67 \\
Brasil & 22,77 & 3,80 & 45,48 \\
Reino Unido & 14,92 & 2,49 & 47,97 \\
Ucrânia & 14,43 & 2,41 & 50,38 \\
Nova Zelândia & 14,08 & 2,35 & 52,73 \\
Itália & 12,41 & 2,07 & 56,84 \\
Polônia & 12,20 & 2,04 & 54,77 \\
Austrália & 11,61 & 1,94 & 58,78 \\
Holanda & 10,84 & 1,81 & 60,59 \\
México & 9,74 & 1,63 & 62,22 \\
Argentina & 8,20 & 1,37 & 63,59 \\
Outros Países & 217,98 & 36,41 & 100,00 \\
T O T A L & 598,69 & 100,00 & \\
\hline
\end{tabular}

Fonte: FAO (2004)

O levantamento preciso do número de produtores de leite no Brasil é uma tarefa bastante difícil, dada a heterogeneidade do sistema de produção, incluindo produtores especializados que produzem um volume grande de leite, até aqueles pequenos produtores, que produzem poucos litros de leite por dia, muitas vezes oriundos de animais para corte.

Para Mesquita (2002) o pequeno produtor não atrela toda sua estrutura econômica ao leite, ou o faz temporariamente, mas desenvolve atividades conjuntas, como pecuária de corte, café, fruticultura, entre outras. No entanto um estudo que pretenda avaliar as perspectivas de sobrevivência e desenvolvimento econômico dessa categoria deveria considerar esses fatores na composição da renda dos pequenos produtores. 
Segundo dados do Instituto Brasileiro de Geografia e Estatística (IBGE), no último censo agropecuário de 1996, existia no Brasil em torno de 1,810 milhão de produtores de leite, número este 3\% menor que o censo de 1985, que registrava aproximadamente 1,870 milhão de produtores.

Dados das 15 maiores indústrias laticinistas do País indicam a existência de 95.847 produtores com produção anual de 6.014.227 litros em 2002. Dessa forma, as quinze maiores empresas de laticínios captaram aproximadamente 26\% da produção brasileira. Entre os anos de 2000 a 2002 verificou-se uma redução de cerca de 22\% no número de produtores. No entanto, o volume captado foi praticamente o mesmo, evidenciando o aumento de escala por produtor, que passou de uma média de 135 litros/dia para 172 litros/dia ${ }^{1}$.

Como pode ser observado na Tabela 2, a Nova Zelândia passou por uma série de mudanças estruturais, as quais o Brasil pode estar começando a atravessar. Inicialmente, observa-se a redução significativa do número de fazendas, aumento do seu tamanho médio e do número de vacas por fazenda, provavelmente pela redução no preço do leite que exigiu uma maior eficiência e produção em escala. Nota-se também que a produção por vaca vem aumentando, devido as constantes pesquisas, melhoramentos genéticos e um melhor conhecimento de nutrição animal e manejo das pastagens. Houve também redução do número de cooperativas, que nos últimos 20 anos passou de 116 para 11, com aumento de tamanho que pode ter elevado a eficiência e o poder de negociação internacional.

\footnotetext{
${ }^{1}$ ver Anexo A.
} 
Tabela 2. Mudanças ocorridas nas últimas décadas na Nova Zelândia

\begin{tabular}{lccccc}
\hline & 1920 & 1950 & 1977 & 1997 & 2001* \\
\hline $\begin{array}{l}\text { Numero de fazendas } \\
\text { (com mais de 10 vacas) }\end{array}$ & 29.111 & 34.367 & 17.363 & 14.741 & 13.982 \\
Vacas/fazenda & 30 & 54 & 112 & 208 & 251 \\
Tamanho médio das fazendas (ha) & - & - & 56 & 86 & 96 \\
Produção por vaca (milksolids) & 138 & 191 & 223 & 301 & 310 \\
& & & & & \\
Número total de vacas (milhões) & 0.890 & 1.820 & 2.080 & 3.060 & 3.485 \\
Número de cooperativas & 538 & 231 & 116 & 11 & 05 \\
\hline
\end{tabular}

Fonte: White \& Hodgson (2000)

* Fonterra Dairy Industry

Ao longo dos dois primeiros anos após o Plano Real, a estabilidade dos preços e o fim do processo inflacionário aumentaram o consumo de leite de 110 litros por habitante, em 1994, para 133 litros, em 1996². Primo (2001) destaca que nos dois anos seguintes o crescimento da renda ficou praticamente estagnado e a redução do nível de atividade fez-se acompanhar do aumento do desemprego, com redução da massa salarial e do aumento da carga fiscal. O mesmo autor afirma que a demanda de produtos lácteos é elástica em relação à renda. Se esta se reduz, a demanda cai mais que proporcionalmente.

Os dados do IBGE mostram uma redução do consumo de leite nos últimos anos. O consumo médio por habitante em 2003 no País é de 130 litros por habitante/ano, sendo que a FAO aponta que o consumo ideal seria de 170 litros por habitante/ano. A diferença representa uma ingestão 23,53\% menor do que a considerada ideal. A demanda por leite e derivados pode ser alterada por diversos fatores, entre eles o crescimento de renda, aumento de população, redução de preços relativos de produtos concorrentes ou substitutos e mudanças nos hábitos alimentares.

\footnotetext{
${ }^{2}$ ver Anexo B.
} 
O potencial produtivo do setor e suas vantagens comparativas brasileiras em relação a outros países produtores, e tradicionais exportadores, deverão ser trabalhados intensamente por centros de pesquisa, universidades, e pela iniciativa privada. A implementação da Portaria 56/99 do Ministério da Agricultura, Pecuária e Abastecimento que regulamenta o Programa Nacional de Melhoria da Qualidade do Leite (PNQL) deverá ser uma das primeiras iniciativas do Brasil para ganhar a credibilidade dos principais e maiores centros importadores de derivados de leite no mundo.

A portaria 56, publicado no diário Oficial da União, em dezembro de 1999 estabeleceu as regras para produção de leite no Brasil. O conjunto de medidas visa a melhoria gradativa da qualidade do leite produzido no Brasil. Entre as novidades mais expressivas desse programa estão: o leite em no máximo três horas após a ordenha deve ser resfriado a $4^{\circ} \mathrm{C}$. No entanto a maioria dos pequenos produtores ainda utiliza os chamados tanques de "imersão", que necessitam aproximadamente 3 horas para resfriar o leite a $4^{\circ} \mathrm{C}$ e o tanque de expansão tem um custo bastante alto. Também será obrigatória a utilização de caminhões-tanques isotérmicos para o transporte de leite das propriedades até as indústrias. Outra implantação seria a necessidade de testes de Contagem de Células Somáticas, Bacterianas e resíduos de antibióticos.

Os objetivos deste programa, a médio prazo, são beneficiar os produtores pela qualidade do leite e acabar com a comercialização do leite tipo C que passará a ser denominado Leite cru resfriado, ou leite pasteurizado, tanto para consumo quanto para fabricação de derivados. A longo prazo o objetivo é acabar com a diferenciação dos diversos tipos de leite e ter somente um único tipo com padrão internacional de qualidade (Kirchof, 2001). 


\subsection{Alterações nos pólos geográficos de produção de leite}

A produção brasileira de leite vem crescendo significativamente desde o início da década de 1990. Essa expansão, no entanto, não é uniforme, sendo bastante variada entre estados e sistemas de produção. Segundo o IBGE, a produção brasileira de leite cresceu 41\% no período de 1990 a 2001. A região Norte acumulou o maior crescimento (122\%), seguida pelo Centro-Oeste com 91\%, região Sul (59\%), Sudeste e Nordeste, com 23\% e 10\%, respectivamente. Considerando que os maiores centros de consumo são as regiões metropolitanas de São Paulo, Rio de Janeiro e Belo Horizonte, conclui-se que a expansão da produção está ocorrendo longe desses mercados.

Segundo Primo (2001), a indústria de laticínios sempre se beneficiou do baixo custo de sua principal matéria-prima, o leite. A produção de leite era praticamente extrativista, ou seja, o leite era obtido como subproduto de rebanhos de corte. A indústria tirava proveito dessas condições favoráveis. Mas o leite era de baixa qualidade e existia uma sazonalidade maior de produção, que, porém, não eram empecilhos já que o consumidor era pouco exigente. O problema de estacionalidade era amenizado pelo pagamento de preço baixo pelo leite extra-cota, como uma forma de financiar a estocagem do produto para ser usado na entressafra.

Para Martins (2002) a produção está migrando de estados tradicionais em leite para o Centro-Oeste, estados do Norte e Bahia, que apresentam menor custo de produção. A produção do estado do Rio Grande do Sul cresceu 45\% entre 1990 a 2000, enquanto Paraná e Goiás se destacaram, com crescimento de 55\% e 100\%. Segundo Galan (2000) o aumento de produção do estado de Goiás surgiu da existência de uma produção residual de leite provinda de rebanhos de corte e vendida a preços muito baixos. Este leite barato, juntamente com incentivos governamentais, atraiu diversos laticínios. Essas novas bacias se sustentam graças ao baixo custo de produção do leite e a facilidade de escoamento para os grandes mercados do sudeste. Nessas bacias predominam grandes empresas multinacionais e inúmeros pequenos e médios produtores. Galan (2000) ainda diz que o aparecimento de matéria-prima barata e as 
novas condições de mercado dos produtos industrializados trouxeram forte redução na remuneração dos agentes e forçou a uma redução dos custos em toda a cadeia.

A realização dessa alteração geográfica foi facilitada pela introdução do leite “Longa Vida” (UHT), que aumentou o tempo de armazenamento do produto, possibilitou a redução da freqüência de entrega, permitindo que os mercados consumidores fossem alcançados pela produção de regiões mais distantes. De acordo com a Associação Brasileira de Leite Longa Vida (ABLV), este produto participava com 4,4\% do total de leite fluido vendido no Brasil em 1990, atingindo 74\% em 2002. (Tabela 3).

Tabela 3. Comportamento das vendas internas de Leite Longa Vida 1990/2002 (em milhões de litros)

\begin{tabular}{lccc}
\hline Ano & Total Leite Fluido (1) & Leite Longa Vida (2) & Participação \% (2)/(1) \\
\hline 1990 & 4.241 & 187 & 4,4 \\
1991 & 3.951 & 204 & 5,2 \\
1992 & 3.693 & 355 & 9,6 \\
1993 & 3.162 & 456 & 14,4 \\
1994 & 3.615 & 730 & 20,2 \\
1995 & 4.200 & 1.050 & 25,0 \\
1996 & 4.535 & 1.700 & 37,5 \\
1997 & 4.720 & 2.450 & 51,9 \\
1998 & 5.080 & 3.100 & 61,0 \\
1999 & 5.125 & 3.425 & 66,8 \\
2000 & 5.230 & 3.600 & 68,8 \\
2001 & 5.390 & 3.950 & 73,3 \\
2002 & 5.700 & 4.220 & 74,0 \\
\hline
\end{tabular}

Fonte: ABLV (2003) 


\subsection{Objetivos}

A prática de preços diferenciados por volume tem sido uma estratégia bastante difundida e utilizada pelas indústrias brasileiras. Mesmo não havendo estudos que relacionem volume com qualidade, cada vez mais as diferenças de preço estão se acentuando entre os produtores com diferentes faixas de produção, o que pode estar levando à exclusão de produtores com escalas pequenas.

O objetivo geral desse trabalho é analisar e discutir a diferenciação de preços do leite em decorrência do pagamento de bonificações por volume, dentro de diferentes linhas de coleta, e tentar avaliar seu possível impacto no sistema agroindustrial do leite.

Stigler (1946) discute as condições para a ocorrência de discriminação de preços. De acordo com esse autor a discriminação ocorre quando não justificada por diferenças correspondentes nos custos. Assim se os custos de coleta de maiores volumes forem menores do que os custos de coleta de menores volumes e essa diferença de custos corresponder à diferença de preços de produtos não há discriminação. Como se desconhece a extensão em que isso ocorre no sistema de pagamentos de leite no Brasil, utiliza-se o termo diferenciação em lugar de discriminação de preços no mercado brasileiro de leite. A possível ocorrência de discriminação será testada na pesquisa.

O trabalho também tem como objetivos específicos:

- Analisar como é determinado e quais as variáveis que mais influenciam na cobrança do frete;

- Analisar os efeitos do número de produtores, captação total por linha e individual sobre o valor de frete e preço recebido por cada produtor;

- Levantar informações sobre sistemas de pagamentos e cobrança de frete dos principais estados produtores. 


\section{REVISÃO DE LITERATURA}

\subsection{Formação dos preços}

Barros et al. (2000) identificaram uma relação de equilíbrio de longo prazo entre os preços ao produtor em diferentes estados e bacias leiteiras. Os preços pré e pósplano real eram e continuam co-integrados. Testes de causalidade identificaram bacias líderes na formação de preços, verificando-se que Minas Gerais é a principal bacia formadora de preços no País, com sentido casual sobre os preços de todas as demais regiões. Uma das principais razões dessa influência pode estar relacionada ao fato da produção desse estado ser pouco inferior à soma das produções do Rio Grande do Sul, São Paulo e Goiás. Os autores ainda afirmam que o sentido da causalidade é apenas de Minas Gerais para os demais estados, não havendo dupla causalidade em nenhuma situação.

As empresas hoje têm um sistema próprio de bonificações e descontos, sendo seu preço final resultado de uma política leiteira. As empresas de médio e grande porte adotam a estratégia de que não pode faltar leite nas indústrias, o que faz que as empresas disputem entre si produtores com maiores volumes e qualidade. Cada indústria tem a liberdade de pagar o que achar necessário. Por exemplo um determinado produtor pode receber mais para viabilizar a linha em que se encontra: é ele que torna viável a coleta do leite dos pequenos produtores que estão nessa rota de leite, sendo que, no final a indústria tem um preço médio adequado a seus custos pelo qual o produto é adquirido (Barros et al., 2001). 
A Holanda e Reino Unido, de acordo com Pennings e Meulenberg (1998), apresentavam flutuações de preços e os produtores estavam expostos a riscos que aumentavam os problemas gerenciais para os produtores. A solução encontrada foi a implantação da venda no mercado futuro, o que teria resolvido os problemas relacionados a diferenciais de preço entre regiões e entre períodos de tempo.

Segundo Franks (2004) entre 1933 e 1994, a Milk Marketing Boards of England and Wales (MMBEW) era a única empresa com direito a comprar e coletar todo o leite das fazendas do Reino Unido. Em 1994 a MMBEW foi desativada e pela primeira vez em 60 anos os produtores puderam escolher para quem vender seu leite. A MMBEW costumava usar uma estratégia de preços de acordo com o destino final do leite, ou seja, leite destinado para o consumo líquido, tinha um maior valor ao produtor do que aquele destinado para produtos processados. O valor cobrado por litro pela coleta e transporte era o mesmo para todos os produtores, o que fazia com que grandes produtores próximos as industrias processadoras subsidiassem pequenos produtores mais distantes. Os sistemas de pagamento foram se alterando ao longo do tempo, e em 1960 o preço estava atrelado a qualidade do produto e anos mais tarde preços sazonais foram implantados para estimular a produção na entressafra.

Franks (2004) também acredita que quando a MMBEW foi extinta mais de 100 compradores de leite começaram a operar, os quais estavam agrupados em 3 grupos, a maior parte eram cooperativas, existiam também aqueles produtores que vendiam direto aos laticínios e a grupos de produtores. Segundo Colman (1992), ${ }^{3}$ citado por Franks (2004) após a extinção da MMBEW, uma única cooperativa, a Milk Marquet, incorporou $65 \%$ dos produtores e $60 \%$ do leite produzido. Isso permitiu que a cooperativa Milk Marquet tivesse um grande poder para regular preços.

\footnotetext{
${ }^{3}$ COLMAN, D. The breakdown of the milk marketing schemes. Oxford Agrarian Studies, v.20, n.2, p.129-138, 1992.
} 
A partir daí algumas processadores e indústrias começaram a oferecer preços maiores do que os pagos pela cooperativa. Esses compradores alegavam que esta estratégia era possível porque eles tinham menores custos administrativos e de coleta e uma estrutura de contratos voltados a obter um leite de maior qualidade. Essa venda direta também permitia muitas inovações, por exemplo, muitos entregavam o leite a cada dois dias, o que reduzia os custos de transferência, também introduziram o sistema de bonificação por volume (o que acabou com a prática dos grandes produtores subsidiar os pequenos) e inovaram com pagamentos por fidelidade. Essas alterações foram responsáveis por uma maior variação nos preços líquidos pagos ao produtor. Outros fatores além do volume também contribuíram para a diferenciação dos preços líquidos, como por exemplo teores de gordura, proteína, Contagem de Células Somáticas (CCS), mês de produção e localização das propriedades.

Um modelo utilizado por Franks (2004) confirma o incentivo financeiro a produtores com maiores volumes. Havia acréscimos financeiros para produtores de 1,5 milhão de litros por ano quando comparado a produtores de 1 milhão de litros.

As razões para instalar o MMBEW na década de 30 foram as dificuldades do mercado de lácteos, a perecibilidade do produto, a tradição de produção familiar com poucos grandes compradores. Mas essas características permanecem até hoje. A desregulamentação do setor em 1994 alterou as práticas de mercado, mas a resposta dos produtores ao novo ambiente claramente demonstrou um suporte para a estrutura de cooperativas. O que permaneceu foi o preço prêmio para o leite destinado ao consumo líquido, mas esse mercado absorve 50\% do leite do Reino Unido e para o produtor entrar nesse seleto grupo de produtores é necessário poder de mercado, volume, qualidade e muito investimento no planejamento da atividade.

Segundo Brandão (2001) a rentabilidade da atividade leiteira é baixa. O baixo retorno por litro faria com que a escala de produção fosse o principal determinante da renda gerada por essa atividade tornando-se um fator importante para explicar a tendência crescente à especialização do setor. Os produtores especializados têm maiores 
estímulos para aumentar o volume de produção, pois dessa forma, além de garantir rendas maiores, ainda se beneficiam de reduções do custo médio de produção, o que decorre na diluição dos custos fixos e dos investimentos, que são bastantes elevados nesta atividade.

No entanto, o sistema de bonificação por volume é a forma mais direta de diferenciar preços e o pequeno produtor vai receber uma remuneração menor do que o grande. Testa et al. (2003) em estudo realizado com produtores de Santa Catarina, identificaram variação de 35\% na média dos grupos, com preços que variavam de R\$ 0,188 para o grupo com os menores volumes e de $\mathrm{R} \$ 0,254$ para o grupo de escala maior. Situação semelhante foi verificada para a cobrança do frete, onde para um frete médio de $\mathrm{R}$ \$ 0,031/ litro, variações de R \$ 0,0197 a R \$ 0,0524 entre os distintos grupos. Acrescentando a bonificação e descontando o frete, as diferenças sobem para $72 \%$ em função do volume vendido.

\subsection{Pagamento por qualidade}

Bandeira (2001) reconhece que o setor lácteo caminha para um ambiente mais competitivo e moderno, mas os consumidores ainda têm impressões pré-concebidas como, “o leite in natura é melhor do que o processado", ou que "o queijo da fazenda é mais gostoso do que o industrial”, o que indica que estes estão mal informados e podem estar consumindo produtos de origem e qualidade duvidosa, permitindo que alguém produza e distribua tais produtos. Isso faz com que o setor apresente uma grande heterogeneidade de sistemas de produção e comercialização, que são sérios gargalos para a melhoria da qualidade e modernização do setor. Dessa forma o mercado operaria sob condições desiguais, um com regras oficiais e outra à margem do sistema legalizado. Diante dessas condições, é difícil difundir entre os produtores a idéia de que vale a pena investir e produzir leite com qualidade superior. 
A qualidade do leite vai melhorar quando o mercado exigir, reconhecer e valorizar produtos com qualidade superior. O pagamento diferenciado seria um instrumento para estimular o produtor a se especializar.

Um pool formado na região de Castro pelas cooperativas Castrolanda e Batavo, no estado do Paraná, foi pioneiro na utilização de padrões de qualidade na remuneração do leite ao produtor e adotam desde junho de 2000, um sistema de pagamento no qual o preço final está baseado em um programa de qualidade que considera teor de gordura, teor de proteína, contagem bacteriana, temperatura do leite no momento da coleta, crioscopia (presença de água no leite), presença de antibiótico e contagem de células somáticas, sendo este último o indicador de maior impacto no preço final. O sistema de pagamento parte de um preço-base sobre o qual incidem premiações e/ou descontos por qualidade, mais uma bonificação pelo volume entregue. As análises são realizadas com todos os produtores, duas vezes por mês, por meio de amostras coletadas nos tanques. O estímulo à melhoria da qualidade valoriza o produto, traz ganhos de produtividade e redução de desperdício na produção, na indústria e no varejo (Bandeira, 2001)

Para Mesquita (2002), a qualidade da matéria-prima não é um atributo específico da grande produção. $\mathrm{O}$ autor segue dizendo que a atividade leiteira requer cuidados detalhados e o pequeno produtor e seus familiares, em princípio, estariam mais aptos para esses cuidados e empregando equipamentos e tecnologia, a família tenderia a compensar a falta do efeito escala com o efeito trabalho.

No entanto, o consumidor é a peça chave para a modernização do sistema Agroindustrial do Leite. É a partir de sua percepção, seu hábito de consumo, sua exigência e, principalmente, sua disposição a pagar, que serão determinadas as novas regras e condições do mercado.

Em um primeiro momento, após a implantação do Plano Real em 1994, houve um aumento por demanda de lácteos superior ao aumento da oferta, o que resultou na entrada de lácteos importados no mercado interno. Segundo Primo (2001) 
esse fato se deve, principalmente, à estabilização econômica e ao ingresso de milhões de consumidores de baixa renda no mercado de consumo, até então restrita às classes de renda mais elevada. Sendo a demanda por derivados lácteos de natureza elástica, a elevação do nível de renda resultou na elevação mais que proporcional na demanda.

Como o consumidor é pouco exigente, as indústrias teriam passado a utilizar matéria-prima barata e de qualidade questionável.

\subsection{Coleta de leite}

O Sistema Agroindustrial do Leite apresenta uma logística especifica de transporte do leite do campo à fábrica. Segundo Silva (1999) esse transporte tem sido tradicionalmente caracterizado por duas etapas distintas. O primeiro percurso ocorre das unidades de produção até um entreposto, no qual o leite é refrigerado e armazenado, e o segundo percurso refere-se ao trajeto destas estações até as unidades processadoras. A tendência é que os produtores entreguem o leite já refrigerado e os caminhões se desloquem direto para as indústrias, reduzindo o número de entrepostos, como uma maneira de reduzir os custos de transporte e armazenamento já que as reduções de custos e o planejamento logístico eficaz são armas importantes para a competitividade dos laticínios.

A atratividade dos caminhões-tanque e das rotas pode ser contabilizada através do cálculo da quantidade de leite transportada por quilometro percorrido, sendo que produtores com maiores volumes seriam mais eficientes para as indústrias. Para Soares (1997) o planejamento da logística deve basear-se no aumento da taxa litros coletados/km rodados, realocando rotas na tentativa de se excluir um ou mais veículos da atividade. A sazonalidade das entregas é outro grande desafio para o gerenciamento, de forma que a relação litragem coletada e quilometragem devem ser monitoradas diariamente. 
Para Caixeta (2002) o alto custo do transporte da fazenda à fábrica é um dos gargalos para o aumento da eficiência no sistema agroindustrial do leite. Da produção ao consumidor, o leite passa basicamente por três percursos: da fazenda aos entrepostos, seguindo então para as indústrias e, enfim, para o local de acesso ao consumidor. O primeiro percurso está baseado em dois sistemas: o transporte tradicional em latões e o granelizado. O transporte em latões compromete a qualidade do leite, pois ao permanecer à espera do caminhão, a temperatura dentro do latão sobe e as bactérias se proliferam rapidamente.

No processo granelizado, após a ordenha, o leite é acondicionado em tanques de expansão, ou tanques de imersão, onde é resfriado. Com a chegada do caminhão,o leite é transferido diretamente para o tanque isotérmico, sem contato manual, no caso dos tanques de expansão, ou os latões que estão acondicionados nos tanques de imersão são transferidos para o tanque do caminhão. Esses tanques de resfriamento ficam nas fazendas, aumentando a qualidade do leite e permitindo que o leite seja coletado de dois em dois dias e não diariamente, o que reduz custos de captação.

A coleta a granel do leite provoca alterações importantes nos setores de produção e indústria. Parece evidente que com eliminação dos pequenos produtores a indústria pode eliminar alguns entrepostos de coleta, devido a granelização permitir uma maior abrangência de coleta, o que representa redução de custos de manutenção e possíveis ganhos de competitividade. Apesar das vantagens apresentadas pelo processo de granelização, o Brasil apresenta problemas estruturais que dificultam a implantação do sistema, como as condições das estradas rurais, falta de energia elétrica, custos de aquisição de resfriadores e pequena escala de produção por propriedade (Caixeta, 2002).

Em algumas situações tem se observado duas ou mais industrias concorrendo numa mesma área, provocando “cruzamento de linhas”, mesmo não tendo plena capacidade de carga para um único veículo. Um gerenciamento logístico eficiente deve prever a coleta de um determinado volume, no menor tempo, com o menor número de caminhões. Logo, as variáveis mais importantes para custo são: o número de veículos 
em operação, a distância envolvida e a escala das operações. No entanto, a dificuldade de previsão de demanda e a incerteza da oferta, também proveniente da ausência de contratos entre produtores e industrias, são aspectos que merecem destaque para o abastecimento de leite no Brasil (Caixeta, 2002). 


\section{METODOLOGIA}

\subsection{Caracterização da pesquisa e coleta de dados}

Trata-se de pesquisa que coletou informações de campo que foram usadas para testar hipóteses sobre a formação do frete e dos preços pagos aos produtores de leite. Foi testada a ocorrência de discriminação de preços no sistema de pagamento aos produtores.

A amostra selecionada abrange linhas de coleta de cooperativas de leite. As características de captação e pagamento das regiões selecionadas não diferem substancialmente dos padrões nacionais, que são relativamente homogêneos.

A seleção da região se deu pela sua importância em nível nacional e pela disposição das cooperativas locais de fornecer os dados necessários, que em função de suas características são de difícil obtenção em outras circunstâncias. A coleta de dados primários se deu por meio de visitas às cooperativas, realizadas pessoalmente pelo próprio autor. Para a obtenção de informações primárias, de maior importância para o entendimento da dinâmica do setor em estudo, foram entrevistados os agentes que atuam nos setores de captação e transporte das cooperativas. A amostra é composta de 1666 produtores, distribuídos em 62 linhas de coleta de cinco cooperativas do Paraná. Os dados foram extraídos de planilhas fornecidas pelos departamentos de captação das empresas, separadas por linhas de coleta, nas quais constam o volume mensal entregue por cada produtor, o valor bruto recebido, o valor descontado de Funrural e Frete, e o valor líquido a receber. As diferenças de preços presentes nas planilhas referem-se 
somente aos diferencias pago por volume, já que as cooperativas selecionadas, na época do estudo ainda não utilizavam o critério de pagamento por qualidade.

Paralelamente foram aplicados questionários a noventa cooperativas e empresas de laticínios dos estados de Goiás, Paraná, Bahia, Rio Grande do Sul, Minas Gerais e São Paulo para fazer um levantamento dos métodos de pagamento que estão sendo utilizados e como está sendo realizada a cobrança de frete ${ }^{4}$. O critério de escolha foi a captação dos estados, segundo o IBGE e o número de estabelecimentos com Serviço de Inspeção Federal.

\subsection{Custo de transferência e preços locais}

Segundo Bressler \& King (1970), como a produção e o consumo estão localizados separadamente, a transferência de produtos, tanto básicos, semi-faturados e faturados, precisam de uma conexão. Este serviço de transferência pode incluir atividades como reunião em terminais de embarque e carregamento, transporte para maiores centros e a distribuição para os centros de consumo, incluindo varejistas e atacadistas. Algumas dessas atividades não estão diretamente relacionadas à distância, mas os custos são claramente funções da distância envolvida. O conjunto de todos esses custos de movimento é chamado de custo de transferência. A parte que está diretamente relacionada à distância é usualmente chamada de custo de transporte, já o custo fixo ou constantes - que independe da distância - é chamado de custo terminal.

A relação entre distância (ao mercado ou ao posto de recebimento da matéria prima) e o custo por unidade transferida é dada pela função de custo de transferência. Alguns tipos de relação custo de transferência e distância estão ilustrados na Figura 1. A linha horizontal A sugere que o custo de transferência é uma constante Ta independente da distância. A linha B decorreria de um sistema no qual as taxas aumentam com a

\footnotetext{
${ }^{4}$ Ver questionário no Anexo C
} 
distância na forma de degraus. Geralmente os correios e algumas empresas ferroviárias utilizam esse tipo de tarifa. Todas as linhas possuem um intercepto que representa o custo terminal (não associado à distância). A linha C representa o caso em que o custo de transporte é uma função linear da distância. A função linear é frequentemente encontrada quando outros fatores além da distância (incluindo tamanho e tipo de equipamento) permanecem constantes. A linha D descreve uma situação em que os custos de transferência aumentam a uma taxa decrescente com a distância. Isso pode ser esperado quando as condições de transferência ou o tipo de carga usada mudam com a distância. Por exemplo, o transporte de leite pode se dar de três maneiras: com a entrega direta da fazenda para o mercado, por caminhões pequenos, geralmente de locais próximos; a concentração em estações e o transporte para a cidade em caminhões maiores e a concentração e transporte em ferrovias de longas distâncias. A cada distância do mercado (ou posto de recebimento), a modalidade mais econômica tende a predominar, com o custo de transferência aumentando com a distância a uma taxa decrescente. Muitas vezes, a transferência se dá mediante a combinação de modalidades de veículos (Bressler \& King, 1970). 
Custo de transferência

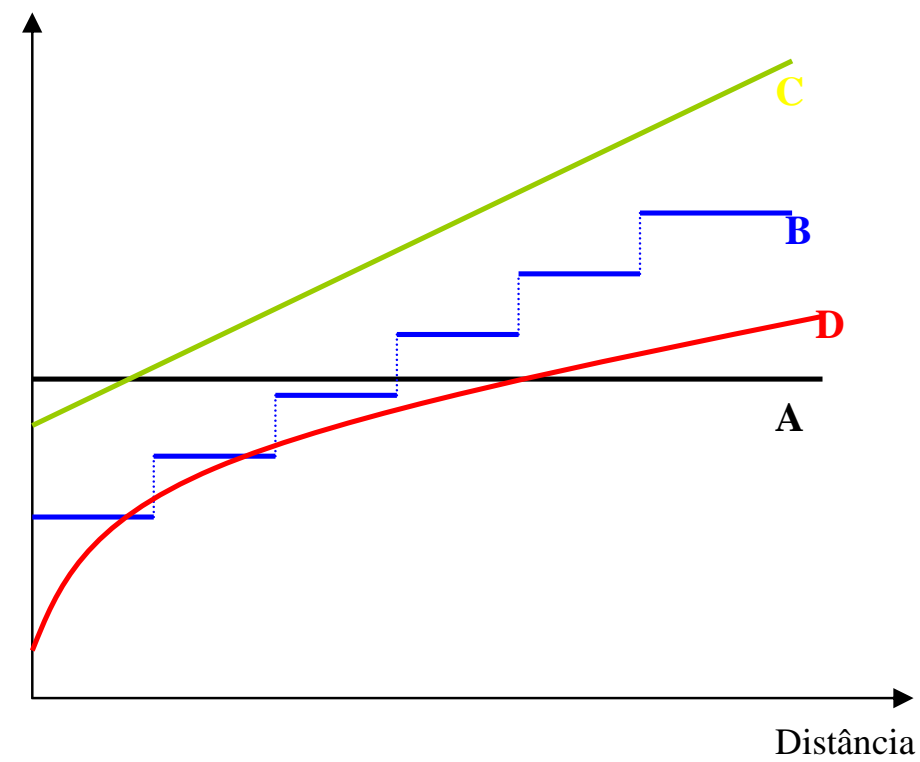

Figura 1 - Distância e custo de transferência

Fonte: Bresler \& King (1970)

No entanto os custos de transferência são influenciados por muitos fatores, como condições das estradas, topografia, além de tipo de carga, tráfego e pedágios. Vale lembrar que os sistemas de transporte estão sujeitos a mudanças e, no longo-prazo, refletem alterações na demanda e nas tecnologias empregadas nos sistemas de transporte.

Para Barros (1985) a superfície de custo de transferência é o padrão de custo de transferência formado a partir de um mercado (ou posto de recebimento) circundado por pontos dispersos de produção, em que o transporte pode-se dar em qualquer direção em condições homogêneas. Considerando uma área uniforme e plana, a superfície pode ser vista transversalmente e projetada num plano. A Figura 2, (a) e (a') foram construídas admitindo-se uma função linear de custo de transferência, enquanto a Figura 2 (b) e (b') admite-se uma função curvilinear. Em ambas as figuras o ponto $M$ representa o mercado 
para o qual se transporta o produto a partir da área ao seu redor. Os valores de $C T_{1}$ a $C T_{4}$ representam custos de transferência que diferem entre si por um valor constante. Nas figuras (a) e (a') as variações nos custos - associados a uma função linear - relacionamse a variações iguais nas distâncias (ou seja, as curvas são eqüidistantes). Nas figuras (b) e (b’) as distâncias aumentam à medida que se transporta de locais mais distantes em razão da curvatura da função de custo.

Na figura 2 a superfície de custo de transferência projetada no plano resulta em círculos concêntricos, cada qual denominado de contorno de isocustos, uma vez que representam os pontos do plano de igual custo de transferência para o mercado em questão. Os contornos de isocustos são desenhados para representar iguais incrementos de custos de transferência de um contorno para o próximo; que é $C T_{1}-C T_{0}=C T_{2}-C T_{1}$ , etc., para cada par de contorno. Com uma função de custo de transferência linear na figura 2 (a) e (a'), estes contornos são igualmente espaçados no plano e distância D1, D2, etc., que representa iguais incrementos em termos de distâncias até o mercado. Já na Figura 2 (b) e (b`), os contornos de isocustos são círculos concêntricos, mas com raios que aumentam com a distância percorrida já que os custos aumentam a uma taxa decrescente (Bressler \& King, 1970). 
a

b

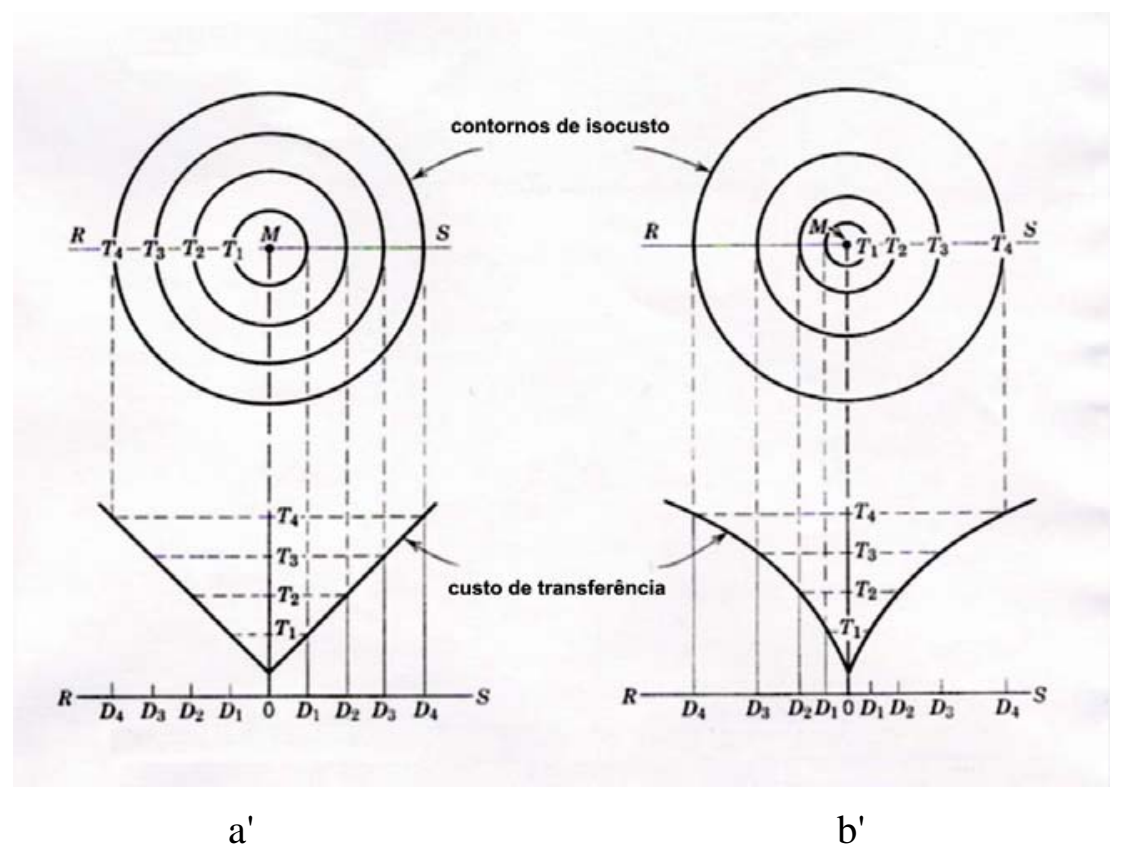

Figura 2 - Superfícies de custo de transferências

Fonte: Bresler \& King (1970)

Barros (1985) acrescenta que o grau de realismo da superfície teórica depende da correlação entre a distância em linha reta do mercado aos pontos de produção e a distância real pelas rotas disponíveis. No mundo real a disponibilidade de rotas apenas em determinadas direções distorcem a simetria apresentada na Figura 2, já que uma área geográfica é caracterizada por diferentes topografias e barreiras naturais. Essas distorções de custos e distâncias podem afetar a simetria das soluções sugeridas pela discussão teórica, mas não os conceitos básicos. Logo, os princípios apresentados através dessa figura são relevantes para análises de questões relacionadas ao transporte.

Em razão do padrão de custos de transferência de produtos das suas regiões de origem para o mercado ou (posto de recebimento), estabelece-se um padrão de preços nos diferentes locais de produção em relação a esse mercado. Ou seja, em torno de cada mercado forma-se um padrão de preços, de tal forma que cada região de produção é 
caracterizada por diferentes níveis de preço cada qual correspondendo a um dado mercado comprador.

Tomando um certo mercado como exemplo, preço-local $\left(P_{L}\right)$ é o preço do produto num determinado local, e é obtido pela diferença entre o preço nesse mercado $\left(P_{M}\right)$ e os custos de transferência $\left(C_{T}\right)$ desse lugar ao mercado, ou seja:

$$
P_{L}=P_{m}-C_{T}=P_{m}-f(d)
$$

Além das superfícies de custos de transferência, fala-se também nas superfícies de preços locais, que pode ser vista transversalmente e projetada no plano. Na Figura 3 observa-se que a distância vertical entre $P_{m}$ e $P_{l}$ é o custo de transferência desse local ao mercado.

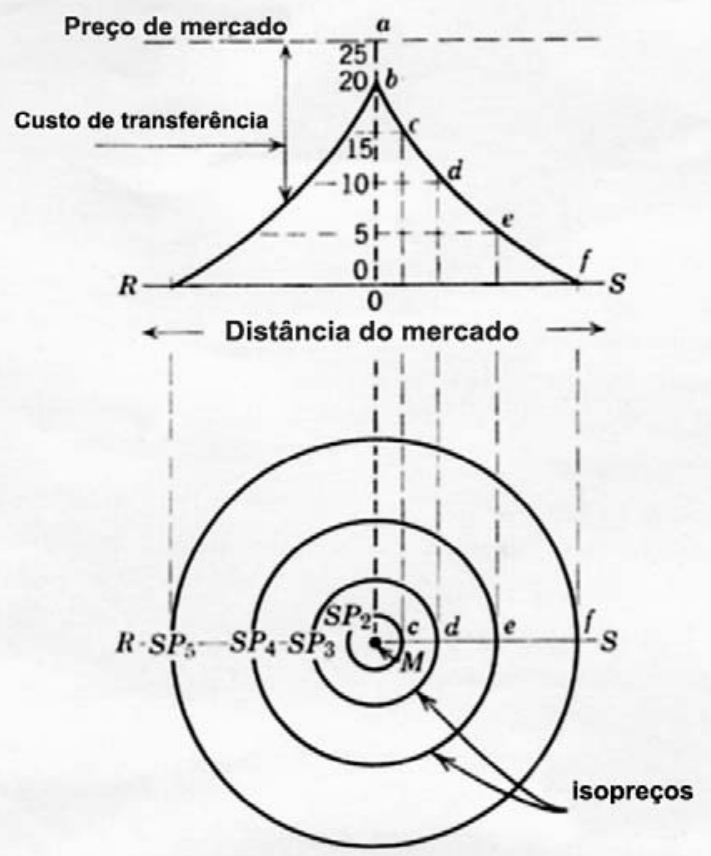

Figura 3 - Superfície de preços locais com produção dispersa Fonte: Bresler \& King (1970) 
Conhecidas às superfícies de preços-locais referentes a diferentes mercados, cada unidade de produção colocará seu produto naquele mercado que lhe oferece o maior preço-local. Embora o custo de produção não afete a decisão de onde colocar o produto, ele será importante para a decisão quanto a produzir ou não o produto em questão. A produção ocorrerá sempre que o preço-local for igual ou maior do que o custo variável médio mínimo (Barros, 1985).

\subsection{Custos de transferência e preços locais: efeitos da falta de concorrência}

\subsubsection{Preços locais e distância}

A lógica por trás da estrutura de preços locais apresentada nas figuras anteriores é a de que, sob concorrência, os compradores competirão entre si pela produção de produtores localizados mais próximos, cujos custos de transferência são menores. Esses compradores deverão ocorrer em número suficientemente grande e em escala suficientemente pequena para que nenhum individualmente possa influenciar o preço pago pelo produto transportado. Quando não há concorrência, a estrutura segundo a qual os preços locais decrescem a partir do mercado (ou ponto de recebimento) de acordo com os custos de transferência pode não se verificar.

Se a estrutura não for competitiva, então o comprador (ou poucos compradores) poderá valer-se do fato de que os produtores mais próximos de dado mercado A - podendo receber preço local mais alto sob competição, $P_{l A}$ - estarão mais distantes de compradores alternativos $\mathrm{B}$, isto é, o preço local alternativo $P_{l B}$ seria bastante inferior a $\mathrm{P}_{I A}$. Embora a estrutura de preços locais ainda permaneça decrescente com a distância, é possível que ela não reflita completamente a estrutura de custos de transferência. Os compradores não competitivos poderiam também pagar um preço único para todos os fornecedores. Em alguns casos, poderia ocorrer de a estrutura inverter-se com preços locais mais altos pagos em locais mais distantes do mercado (ou 
posto de recebimento), normalmente nas divisas entre duas áreas de mercado ${ }^{5}$. O limite para tais práticas é o próprio custo de transporte: preços maiores para regiões mais distantes tende a estimular a produção nesses locais onerando os custos totais de transferência. Ou seja, naturalmente os compradores preferirão ser abastecidos mais expressivamente por fornecedores localizados nas proximidades do posto de recebimento. Essa questão evidentemente está relacionada ao Custo Marginal (CMa) de produção da matéria prima a ser transportada. Quanto mais elástica for a função de $C M a$ mais a produção responde a preços e mais caro será adotar uma estrutura de preços locais que não reflita os custos de transferência. Se a curva de CMa for inelástica, por exemplo, então a produção não se alteraria por causa do preço local e qualquer estrutura de preços locais levaria ao mesmo custo de transporte.

Outro aspecto deve ser considerado no que tange à estrutura de preços locais. Normalmente a coleta é feita por rotas de forma que em cada uma atua um único transportador, por ser esta alternativa a que minimiza o custo de transferência. Mais do que um transportador numa certa rota, leva a duplicações de esforços, aumentando desnecessariamente a distancia total percorrida para coletar a produção de certa região (Barros, 1985). Esse fato pode permitir ao transportador cobrar dos fornecedores tarifas de transporte cuja estrutura não reflete necessariamente a estrutura de custos, podendo ocorrer a cobrança de tarifa única por fornecedor. Mais grave é que pode cobrar tarifas monopolísticas caso não haja transportadores em potencial para entrar no mercado de transporte e forçar a cobrança de tarifas competitivas.

É importante, assim, verificar se os dados coletados para o mercado de leite indicam a vigência de uma estrutura competitiva ou não. Tanto os valores de frete cobrados como os preços locais recebidos devem ser influenciados pela distância percorrida, os primeiros positivamente e os segundos negativamente. Caso tal ocorra tem-se condições necessárias para competição. Não são suficientes porque não se sabe

\footnotetext{
${ }^{5}$ Entende-se por área do mercado A como a região para a qual todos os preços locais são maiores nesse mercado que em outros alternativos. No limite entre duas áreas de mercados A e B, $P_{l A}=P_{l B}$.
} 
em que grau as estruturas de frete e preço local - embora crescente e decrescente com a distância - refletem ambas os custos de transporte.

\subsubsection{Preços locais e tamanho de fornecedores}

A estrutura de preços locais concorrencial supõe que não haja diferenças de custos de transferência decorrente de diferenças de tamanho de fornecedores. $\mathrm{Na}$ verdade, espera-se que haja tais diferenças, sendo mais econômico coletar dado volume de produção de um único produtor do que dois ou mais. Quando determinada rota (associada a certo volume) é entregue a determinado transportador, seu custo depende de quantos pontos de coleta existem na rota. Sendo isso verdade, espera-se que para uma mesma distância do mercado (ou posto de recebimento) um fornecedor de grande volume receba um preço local maior do que um fornecedor de pequeno volume. Dessa forma, não é necessariamente indicação de prática discriminatória a observação de pagamento de preços maiores a produtores de maior volume. Aliás, espera-se que mesmo em competição, tais produtores recebam preços maiores. A questão é que sob competição diferenças de preços devem refletir diferenças nos custos de transferência. Porém, tal verificação pode não ser factível na prática por falta de informação. Na parte empírica deste trabalho propõe-se procedimento para elucidar esta questão.

\subsection{Funções de custo de transferência e preços locais}

O modelo econômico empregado procura explicar a formação do chamado Preço Local $\left(P L_{i k}\right)$ recebido pelo produtor $i$ da cooperativa $k$. (Barros, 1985 e Bressler \& King, 1970). Supõe-se que o produtor $i$ esteja localizado a uma distância $d_{i k}$ da rota $r_{j k}$, com número $n_{j k}$ de produtores na linha de coleta, da cooperativa $k$ e que ele entregue $v_{i}$ litros de leite por unidade de tempo. Parte-se da função de custo de transporte (frete = $C T_{i k}$ ), correspondente a custo por unidade de produto transportada (ex.: $\left.R \$ / l\right)$ dada por: 


$$
C T_{i k}=f\left(d_{i k}, n_{j k}, r_{j k}, v_{i}\right)
$$

Supõe-se que o custo de transporte cresça com a distância da propriedade à cooperativa $\left(\delta C t_{i k} / \delta d_{i k}>0\right)$. Não se dispondo da distância percorrida para coletar a produção de cada produtor individual, opta-se por utilizar a distância total da rota em que o produtor se acha. Pretende-se testar as hipóteses de que o custo de coleta decresça com o volume transportado $\left(\delta C t_{i k} / \delta v_{i}<0\right)$ e aumente com o número de produtores na rota $\left(\delta C t_{i k} / \delta n_{j k}>0\right)$. Define-se, então, preço-local como sendo:

$$
P L_{i k}=P_{k}-C T_{i k}
$$

logo:

$$
P L_{i k}=g\left(d_{i k}, n_{j k}, r_{j k}, v_{i}\right)
$$

onde $P_{k}$ é o preço posto na cooperativa $k$. Para que tal hipótese se concretize é necessário supor que haja concorrência no mercado do produto de sorte que os diferentes compradores disputem a produção dos produtores localizados mais próximos do mercado e daqueles que produzem maiores volumes.

Pretende-se estimar por Mínimos Quadrados Ordinários os modelos (1) e (2') Termos quadráticos de $n_{j k}$ e $v_{i}$ serão incluídos para verificar a possibilidade de nãolinearidade dos efeitos dessas variáveis. Além das variáveis indicadas, o modelo deve incluir variáveis binárias captando as diferentes rotas analisadas. As estimativas das equações (1) e (2') podem ser vistas como alternativas equivalentes. Ou seja, na equação (1), verificam-se os efeitos do volume, do número de produtores e da distância sobre o frete cobrado; na equação (2'), medem-se os efeitos das mesmas variáveis sobre o Preço Local.

A diferenciação de preços, em tese, deveria ser totalmente explicada pelas diferenças de fretes; ou seja, numa equação em que a variável dependente fosse o Preço Local e uma das explicativas fosse o frete, então a inclusão do volume entregue pelo 
produtor como uma segunda variável explicativa não deveria resultar em coeficiente significativo a menos que o volume influenciasse o Preço Local por outras razões que não através do frete. Tal ocorrência, salvo melhor juízo, sugeriria possível discriminação de preços - ou seja, uma diferenciação de preços não devida aos custos de transporte. Veja que se fala apenas em possível discriminação de preços, porque o volume produzido pode estar correlacionado, por exemplo, à qualidade do leite, com o que ele poderia afetar o Preço Local de outra maneira que não através do frete. Se a qualidade do leite dos maiores produtores for superior, a diferenciação de preço não seria necessariamente uma discriminação de preços. Tal discriminação pode aparecer na prática como sendo atribuída ao maior poder de barganha dos maiores produtores, por exemplo.

Para realizar tal experiência será estimado o modelo a seguir:

$$
P L_{i k}=h\left(C T_{i k}, v_{i}\right)
$$

Se a variável volume apresentar coeficiente significativo fica favorecida a sugestão de discriminação de preços. 


\section{RESULTADOS E DISCUSSÃO}

\subsection{Sistemas de pagamento e cobrança de frete}

Para a pesquisa de levantamento de formas de pagamento e cobrança de frete selecionaram-se 87 cooperativas/empresas de seis estados brasileiros às quais foi aplicado um questionário por telefone em dezembro de 2003 (Tabela 4). As cooperativas amostradas correspondem àquelas já presentes no levantamento de preços realizados regularmente pelo Centro de Estudos Avançados em Economia Aplicada (CEPEA), da Escola Superior de Agricultura “Luiz de Queiroz” (ESALQ), da Universidade de São Paulo (USP). Dentro do possível procurou-se uma amostragem eqüitativa em relação à produção de leite e ao número de cooperativas/empresas amostradas.

Assim, o estado de Minas Gerais contribuiu com o maior número de empresas amostradas, seguido de São Paulo e Rio Grande do Sul. No entanto, essa relação não é totalmente válida, pois os estados apresentam um número de estabelecimento que não está relacionado com a produção do estado. O estado de São Paulo, por exemplo, apresenta cerca de 185 estabelecimentos com SIF (Serviço de Inspeção Federal) segundo o Ministério da Agricultura. E o estado de Goiás, mesmo apresentando uma produção maior, tem cerca de 135 estabelecimentos com SIF. 
Tabela 4. Estados amostrados e suas respectivas participações na produção total de leite no Brasil e número de cooperativas pesquisadas

\begin{tabular}{lccc}
\hline $\begin{array}{l}\text { Estados } \\
\text { amostrados }\end{array}$ & $\begin{array}{c}\text { \% da produção formal } \\
\text { brasileira em 2003 }\end{array}$ & $\begin{array}{c}\text { Número de } \\
\text { cooperativas }\end{array}$ & $\begin{array}{c}\text { \% das } \\
\text { cooperativas }\end{array}$ \\
\hline SP & 11,6 & 21 & 24,14 \\
PR & 6,34 & 11 & 12,64 \\
GO & 8,93 & 6 & 6,90 \\
MG & 19,83 & 25 & 28,74 \\
BA & 1,14 & 6 & 6,90 \\
RS & 7,43 & 18 & 20,69 \\
Total & & 87 & 100,00 \\
\hline
\end{tabular}

Diferentemente de diversos países considerados avançados na produção leiteira, a grande maioria das empresas brasileiras ainda não remunera os produtores com base somente na qualidade do leite produzido. Dos estados pesquisados, o maior percentual de cooperativas que pagam por qualidade foi observado nos estados do Paraná e São Paulo, sendo que em casos extremos como Bahia e Goiás não foram encontradas cooperativas que paguem exclusivamente por qualidade (Figura 4 e Tabela 5). Assim, na maior parte das regiões pesquisadas, o pagamento ocorre pela combinação entre volume coletado e qualidade do leite, já que apenas nos estados de São Paulo e Bahia o percentual de cooperativas que pagam apenas por volume foi maior que a combinação destas duas variáveis. 


\section{Formas de pagamento}

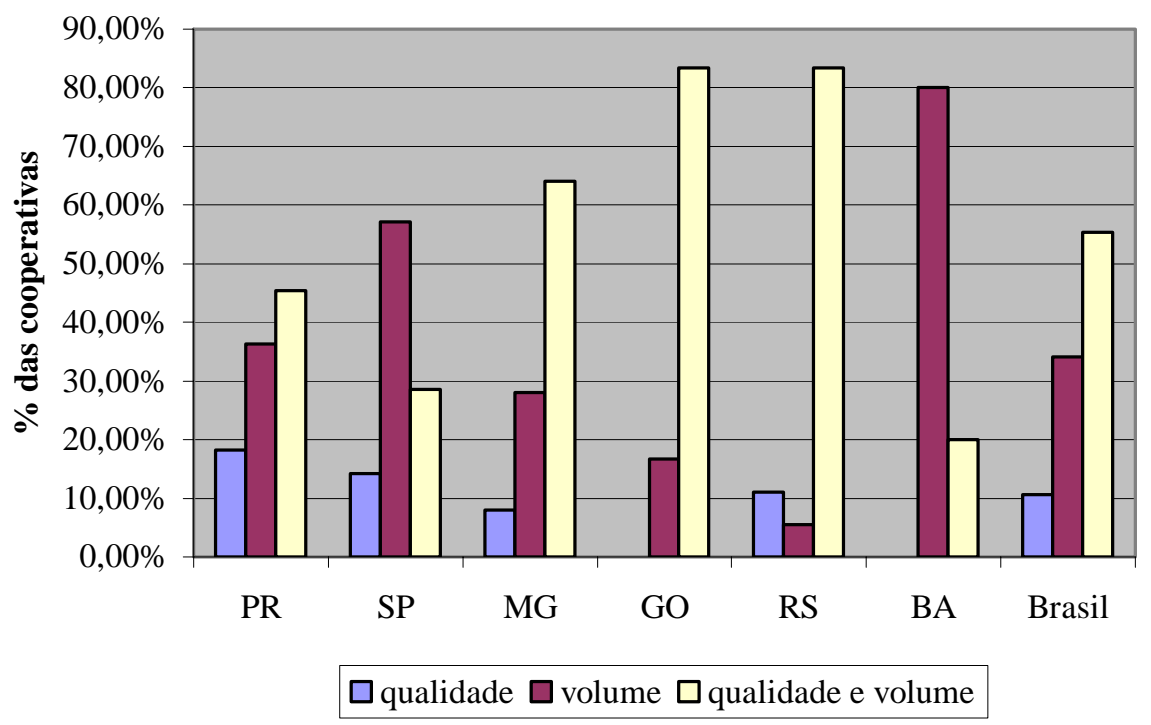

Figura 4 - Representação percentual do pagamento por qualidade, volume e qualidade e volume em diferentes estados brasileiros

Isso evidencia que num País de dimensões continentais como o Brasil, com cooperativas muitas vezes distantes dos produtores, deve haver uma compensação pela quantidade de leite entregue e, sempre que possível, associado com uma qualidade também satisfatória. Já em países menores, como a Nova Zelândia, e onde a logística de coleta é mais eficiente, normalmente não se premia por volume coletado, apenas exigese uma quantidade mínima por produtor, sendo que o preço pago é única e exclusivamente dependente da qualidade do leite entregue. 
Tabela 5. Formas de pagamento aos produtores de leite (\%) em diferentes estados do Brasil

\begin{tabular}{lccccccc}
\hline Formas & \multicolumn{7}{c}{ Estados brasileiros } \\
\hline & PR & SP & MG & GO & RS & BA & \\
Qualidade & 18,18 & 14,29 & 8,00 & 0,00 & 11,11 & 0,00 & 10,59 \\
Volume & 36,36 & 57,14 & 28,00 & 16,67 & 5,56 & 80,00 & 34,12 \\
Qualidade e volume & 45,45 & 28,57 & 64,00 & 83,33 & 83,33 & 20,00 & 55,29 \\
\hline
\end{tabular}

Para a maioria dos estados abordados neste estudo, basicamente o preço do frete é calculado com base no volume coletado. Apenas na Bahia a distância contribui mais que o volume na formação do preço do frete (50\%), como pode ser observado na Tabela 6. Em casos como o Paraná e Rio Grande do Sul, mais de 70\% do valor dos fretes é calculado com base em volume apenas. Parece haver uma correlação positiva entre a formação do preço do frete e dimensão territorial do estado em questão (ou logística de coleta) já que, nos casos de estados com dimensões territoriais maiores como Bahia e Minas Gerais, a distância, como fator isolado, está contribuindo mais na formação do preço que os outros estados. Do outro lado, no caso de estados menores como o PR e RS, as distâncias entre as cooperativas e os produtores poderiam ser relativamente mais curtas, e a componente distância pode ser considerada um efeito menor.

Tabela 6. Contribuição do volume e quantidade coletada na formação do preço do frete (\%) em diferentes estados brasileiros

\begin{tabular}{|c|c|c|c|c|c|c|c|}
\hline & \multicolumn{6}{|c|}{ Estados brasileiros } & \multirow[t]{2}{*}{ Brasil } \\
\hline & MG & PR & GO & RS & SP & BA & \\
\hline Volume & 48,00 & 80,00 & 50,00 & 72,22 & 57,89 & 16,67 & 58,33 \\
\hline Distância & 32,00 & 10,00 & 16,67 & 11,11 & 26,32 & 50,00 & 22,62 \\
\hline Volume e distância & 20,00 & 10,00 & 33,33 & 16,67 & 15,79 & 33,33 & 19,05 \\
\hline
\end{tabular}




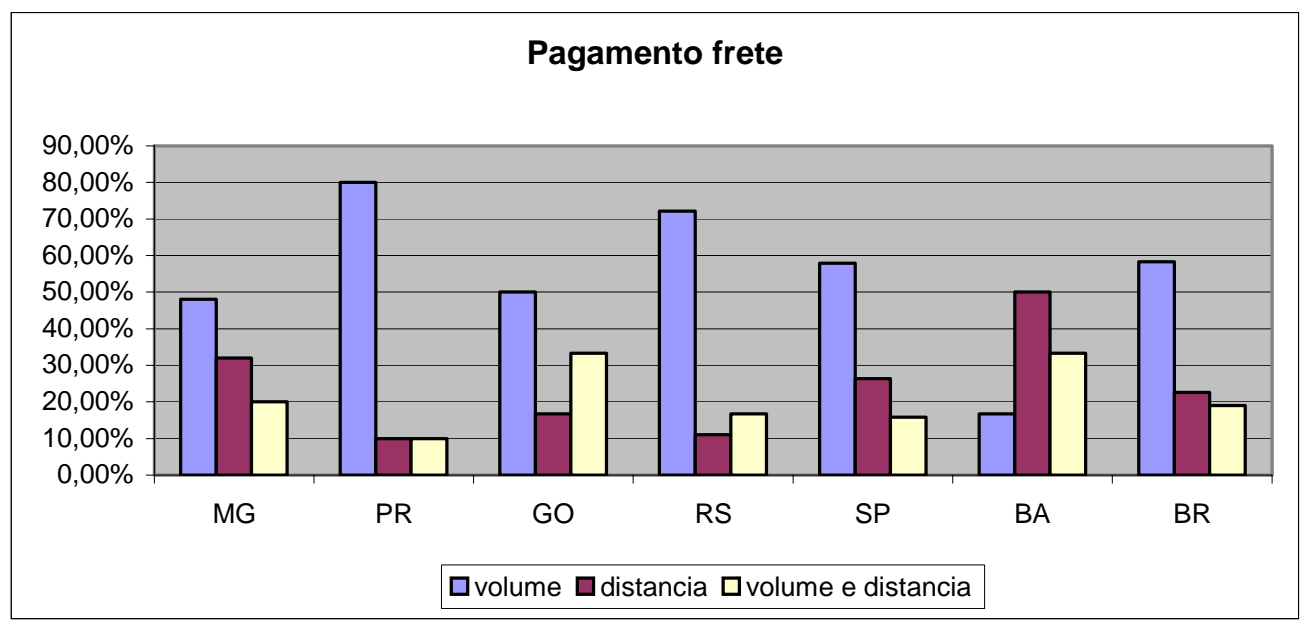

Figura 5 - Representação percentual do pagamento por qualidade, volume e qualidade e volume na formação do preço do frete em diferentes estados brasileiros

\subsection{Variação de preços e cobrança de frete}

Os dados coletados dos 1666 produtores foram ordenados de forma crescente segundo o volume mensal de leite vendido em outubro de 2003. O grupo de produtores foi distribuído em quintis, sendo calculadas as médias de valores líquidos recebidos, volume mensal e diário, frete total e frete por litro.

O volume total captado na amostra foi de 4.300 .810 litros, em 63 linhas de coleta de cinco cooperativas. A média geral de volume entregue foi de 106 litros/dia por produtor, com um mínimo de 0,6 litro até um valor máximo de 3.983 litros/dia para o maior produtor (Tabela 7). As diferenças pagas pelo frete também foram muito variáveis, sendo que a média da amostra foi de R\$ 0,029/litro, com a amplitude de valores oscilando de zero até $\mathrm{R} \$ 0,070$ por litro. O valor líquido recebido por litro apresentou uma média de $\mathrm{R}$ \$ 0,373, com um mínimo de R 0,255 e um valor máximo de R 0,541 , ou seja, variação de $112 \%$. 
Tabela 7. Valores médios e totais do volume de leite entregue e frete pago por 1.666 produtores de cinco cooperativas, 2003

\begin{tabular}{lcccc}
\hline & Média & Desvio Padrão & Mínimo & Máxima \\
\hline R\$/litro & 0,373 & 0,039 & 0,255 & 0,541 \\
Volume mensal (litros) & 3.180 & 7.954 & 18 & 119.508 \\
frete total (R\$) & 68,32 & 123,05 & 0,00 & $2.902,04$ \\
Pagto liquido (R\$) & $1.336,78$ & $3.893,01$ & 6,11 & $57.244,33$ \\
frete/litro (R\$) & 0,029 & 0,011 & 0,000 & 0,070 \\
litros/dia & 106,00 & 265,14 & 0,60 & $3.983,60$ \\
total (litros) & 4.380 .810 & & & \\
\hline
\end{tabular}

O primeiro quintil apresentado na Tabela 8 representou 1,57\% do volume total captado. A média desse grupo de produtores foi de 8,35 litros por dia. A média do frete/litro foi de R \$ 0,354. Analisando os valores mínimo e máximo observam-se valores com uma grande amplitude, tanto na variável frete/litro como $\mathrm{R} \$$ /litro, demonstrando que pode haver estratégias diferentes de pagamento dentro das diferentes rotas de coleta e cooperativas pesquisadas. O valor líquido médio recebido pelo litro do leite no primeiro quintil foi de $\mathrm{R} \$ 0,354$, valor este dois centavos inferior à média da amostra geral, que foi de $\mathrm{R} \$ 0,373$. 
Tabela 8. Resumo do primeiro quintil

\begin{tabular}{lcccc}
\hline & \multicolumn{3}{c}{ Distribuição dos produtores no primeiro quintil } \\
Q1 & Média & Desvio Padrão & Mínimo & Máxima \\
\hline R\$/litro & 0,354 & 0,040 & 0,269 & 0,469 \\
Volume mensal (litros) & 250 & 123 & 18 & 452 \\
frete total (R\$) & 7,61 & 4,59 & 0,00 & 30,59 \\
pagto liquido (R\$) & 88,85 & 45,03 & 6,11 & 211,99 \\
frete/litro (R\$) & 0,030 & 0,010 & 0,000 & 0,070 \\
litros/dia & 8,35 & 4,09 & 0,60 & 15,07 \\
\hline
\end{tabular}

O segundo quintil correspondeu a 4,21\% da captação total da amostra, com 223.415 mil litros no mês. A média dos produtores desse quintil foi de 22,31 litros por dia, e o valor recebido pelo litro do leite foi de $\mathrm{R} \$ 0,361$, valor líquido, descontado o frete, Funrural e taxas administrativas (Tabela 9).

Tabela 9. Resumo do segundo quintil

\begin{tabular}{lcccc}
\hline Q2 & Média & Desvio Padrão & Mínimo & Máxima \\
\hline R\$/litro & 0,361 & 0,033 & 0,255 & 0,469 \\
Volume mensal (litros) & 670 & 135 & 453 & 916 \\
frete total (R\$) & 20,14 & 7,87 & 0,00 & 61,95 \\
pagto liquido (R\$) & 241,72 & 53,99 & 140,61 & 382,24 \\
frete/litro (R\$) & 0,030 & 0,009 & 0,000 & 0,070 \\
litros/dia & 22,34 & 4,51 & 15,10 & 30,53 \\
\hline
\end{tabular}

No terceiro quintil (Tabela 10) os produtores receberam em média um valor líquido por litro de R\$ 0,364. No entanto, observa-se que o desvio vem reduzindo em relação aos dois primeiros quintis, uma vez que o valor mínimo vem aumentando. A 
produção diária média por produtor foi de aproximadamente 44 litros e a captação desse quintil equivale a 8,29\% da captação total.

Tabela 10. Resumo do terceiro quintil

\begin{tabular}{lcccc}
\hline Q3 & Média & Desvio Padrão & Mínimo & Máxima \\
\hline R\$/litro & 0,364 & 0,029 & 0,286 & 0,469 \\
volume mensal & 1319 & 252 & 916 & 1767 \\
frete total & 39,19 & 14,88 & 0,00 & 117,26 \\
pagamento liquido & 481,56 & 106,54 & 274,96 & 740,55 \\
frete/litro & 0,030 & 0,010 & 0,000 & 0,070 \\
litros/dia & 43,98 & 8,41 & 30,53 & 58,90 \\
\hline
\end{tabular}

O quarto quintil, apresentado na Tabela 11, correspondeu a produtores com produção média de 84 litros, e um valor médio líquido recebido de R\$ 0,377 por litro de leite entregue, com um mínimo de R\$ 0,303 e um valor máximo de R\$ 0,469. A amostra representou $15,76 \%$ do volume total coletado, e os 333 produtores pagaram um valor médio de frete de $\mathrm{R} \$ 0,03$ centavos por litro, assim como os quatros primeiros quantis.

Tabela 11. Resumo do quarto quintil

\begin{tabular}{lcccc}
\hline Q4 & Média & Desvio Padrão & Mínimo & Máxima \\
\hline R\$/litro & 0,377 & 0,028 & 0,303 & 0,469 \\
Volume mensal & 2514 & 490 & 1768 & 3592 \\
frete total & 74,23 & 34,15 & 0,00 & 246,33 \\
pagamento líquido & 949,80 & 210,67 & 567,54 & $1.664,95$ \\
frete/litro & 0,030 & 0,011 & 0,000 & 0,070 \\
litros/dia & 83,81 & 16,35 & 58,93 & 119,73 \\
\hline
\end{tabular}


O quinto e último quintil englobou um grupo de produtores que entregou cerca de 70\% do volume coletado. O grupo apresentou uma média de 368,82 litros/dia, com valores mínimo e máximo de aproximadamente 120 e 3980 litros, respectivamente. O valor líquido médio recebido foi de $\mathrm{R} \$ 0,412$ e o frete médio por litro de $\mathrm{R} \$ 0,024$, como pode ser observado na Tabela 12.

Tabela 12. Dados referentes ao último quintil

\begin{tabular}{lllll}
\hline Q5 & Média & Desvio & Mínimo & Máxima \\
\hline R\$/litro & 0,412 & 0,033 & 0,306 & 0,541 \\
Volume mensal & 11064 & 15268 & 3593 & 119508 \\
frete total & 199,09 & 223,17 & 0,00 & 2902,04 \\
Pagamento liquido & 4885,11 & 7682,85 & 1098,79 & 57244,33 \\
frete/litro & 0,024 & 0,012 & 0,000 & 0,070 \\
litros/dia & 368,82 & 508,95 & 119,77 & 3983,60 \\
\hline
\end{tabular}

Os dados apresentados permitem avaliar os impactos do sistema de pagamento do leite (bonificação por volume) nos valores líquidos recebidos pelos produtores. Assim, na Tabela 13, no qual estão apresentados os resumos dos quintis, observa-se que os valores dos preços líquidos por litro vão aumentando à medida que o volume médio entregue por dia vai tendo acréscimos. Produtores com vendas médias de 83,81 litros receberam em média, R\$ 0,377/litro, enquanto o grupo com venda média de 368,82 litros recebeu $\mathrm{R} \$$ 0,412 por litro de leite, ou seja, os produtores com as maiores vendas receberam um valor 9,28\% maior do que os de menor volume.

Ao analisar o volume total entregue por cada grupo, observa-se que o maior volume de leite, cerca de 3 milhões de litros, é entregue por $20 \%$ dos produtores. Outro dado expressivo é que $60 \%$ dos produtores entregam até 58 litros/dia e representaram apenas 14,13\% do volume captado pelas cooperativas em Outubro de 2003. 
Tabela 13. Valores recebidos, volume de leite entregue e frete pago por 1.666 produtores de cinco cooperativas, 2003

\begin{tabular}{lcccc}
\hline Resumo dos quintis & R \$/litro & frete/litro & litros/produtor/dia & \% do total \\
\hline Q1 & 0,354 & 0,030 & 8,35 & 1,58 \\
Q2 & 0,361 & 0,030 & 22,34 & 4,23 \\
Q3 & 0,364 & 0,030 & 43,98 & 8,32 \\
Q4 & 0,377 & 0,030 & 83,81 & 15,86 \\
Q5 & 0,412 & 0,024 & 368,82 & 70,01 \\
\hline
\end{tabular}

\subsection{Preços do leite ao produtor: efeitos do tamanho}

Para analisar a questão da fixação do preço do leite ao produtor, principalmente no que se refere ao volume produzido, novamente foi utlizada a amostra de produtores de 5 cooperativas brasileiras. Essas 5 cooperativas recolhiam leite de 1.666 produtores de 63 linhas. No entanto, foi excluída uma linha que não trazia todas as informações necessárias para a estimativa das equações, o que resultou em trabalhar com a produção de 1.613 produtores organizados em 62 rotas ou linhas de coleta. Os dados se referem ao mês de outubro de 2003. Como foi demonstrado anteriormente o volume produzido variava de 0,6 litro a 3.983 litros por dia, com uma média de 107,5 litros.

As estimativas das equações propostas na metodologia, para os dados obtidos de cooperativas, estão nas Tabelas 14 e $15^{6}$ :

\footnotetext{
${ }^{6}$ Termos quadráticos de $n_{j k}$ e $v_{i}$ foram incluídos para verificar a possibilidade de não-linearidade dos efeitos dessas variáveis. Além das variáveis indicadas, o modelo inclui 33 variáveis binárias captando as 34 rotas analisadas. A amostra inclui apenas as 1040 propriedades para as quais obteve-se informação sobre a distância percorrida na rota.
} 
Tabela 14. Influência do volume individual e do número de produtores na linha no frete pago pelo produtor

\begin{tabular}{llll}
\hline Variável dependente $=$ CT & Variável & Coeficiente & Valor t \\
\hline Variáveis explicativas & Constante & 0,0246759 & $(-1,12)$ \\
& Vol & $-9,72 \times 10^{-7}$ & $(-31,26)$ \\
& Vol $^{2}$ & $7,66 \times 10^{-12}$ & $(18,60)$ \\
& Nprod & 0,0002789 & $(4,19)$ \\
& Nprod & \\
& Distância & $7,10 \times 10^{-06}$ & $(-3,57)$ \\
& 0,0000215 & $(2,36)$ \\
\hline
\end{tabular}

Número de observações $=1039 ; \mathrm{R}^{2}=0,9158 ; \mathrm{R}^{2}$ ajustado $=0,9127$ onde:

CT = Custo de transferência, frete por litro pago em Reais pelo produtor;

Vol = Volume individual coletado no mês em litros;

$\mathrm{Vol}^{2}=$ Quadrado do volume individual coletado no mês em litros;

Nprod = número de produtores da linha;

Nprod $^{2}=$ quadrado do número de produtores.

Colocando na forma algébrica resultou em:

$$
\begin{aligned}
C T_{i k}= & 0,012+2,15 \times 10^{-5 * *} d_{i k}+2,78 \times 10^{-4^{*}} n_{j k}-2,92 \times 10^{-6^{*}} n_{j k}^{2}- \\
& -9,72 \times 10^{-7^{*}} v_{i}+7,66 \times 10^{-12^{*}} v_{i}^{2}
\end{aligned}
$$

onde um asterisco corresponde a significância a 1\% e dois asteriscos a $5 \%$. O valor de $\mathrm{R}^{2}$ foi 0,92 e $\mathrm{F}=294$ é significativo a 1\%. A amostra continha 1040 produtores. As variáveis são definidas da seguinte maneira: (a) $d_{i k}$ refere-se à distância (ida e volta) da 
rota em km (com média de $175 \mathrm{~km}$ ), (b) $\mathrm{n}_{\mathrm{jk}}$ refere-se ao número de produtores na linha (média de 48), (c) $v_{i}$ mede o volume mensal de leite entregue pelo produtor em litros (média de 3.081) e (d) $\mathrm{CT}_{\mathrm{ik}}$ é medido em $\mathrm{R} \$ /$ litro (com média de $\mathrm{R} \$ 0,03$ ).

O valor médio do frete pago pelo produtor tem um valor fixo de $\mathrm{R} \$ 0,012$ por litro (intersecção). A esse valor acresce-se $\mathrm{R} \$ 0,0038$ por litro para uma distância de média de $175 \mathrm{~km}$. Considerando um número médio de 48 produtores por rota, deve-se somar R\$0,0066 por litro. Finalmente, tomando um volume médio de 3081 litros/mês, deve-se subtrair R\$0,0029 por litro. Pode-se verificar que o valor do frete tende a cair para o produtor até o volume de 63,5 mil litros/mês. Analogamente, pode-se verificar que frete de determinada rota tende a cair até o número de 48 produtores, passando a crescer a partir de então.

Tabela 15. Influência do volume individual e do número de produtores na linha no preço líquido recebido

\begin{tabular}{cccc}
\hline Variável dependente $=$ PL & & & \\
& Variável & Coeficiente & Valor t \\
\hline Variáveis explicativasConstante & 0,3576353 & $(143,48)$ \\
Vol & $5,84 \times 10^{-6}$ & $(31,01)$ \\
Vol $^{2}$ & $-4,57 \times 10^{-11}$ & $(-20,12)$ \\
Nprod & $-0,0004654$ & $(-3,89)$ \\
Nprod $^{2}$ & $7,10 \times 10^{-06}$ & $(5,52)$ \\
\hline
\end{tabular}

Número de observações $=1613 ; \mathrm{R} 2=0,4610 ; \mathrm{R} 2$ ajustado $=0,4596$

onde:

PL = Preço Local, líquido ao produtor em reais;

Vol = Volume total por produtor coletado no mês em litros;

$\mathrm{Vol}^{2}=$ Quadrado do volume total por produtor coletado no mês em litros;

Nprod = número de produtores da linha;

Nprod $^{2}=$ quadrado do número de produtores. 
O que resultou em:

$$
\begin{aligned}
P L_{i k} & =0,358-4,65 \times 10^{-4^{*}} n_{j k}+7,10 \times 10^{-6^{*}} n_{j k}^{2}+ \\
& +5,84 \times 10^{-6^{*}} v_{i}-4,57 \times 10^{-11^{*}} v_{i}^{2}
\end{aligned}
$$

onde um asterisco corresponde a significância a 1\%. A amostra continha 1613 produtores $^{7}$. Neste caso, verifica-se que o Preço Local médio tem um valor fixo de $\mathrm{R} \$ 0,358$ por litro (intersecção). Desse valor subtrai-se $\mathrm{R} \$ 0,0065$ por litro para um número médio de 45 produtores por rota. Tomando um volume médio de 3227 litros/mês, deve-se aumentar o Preço Local de R\$0,018 por litro. Pode-se verificar também que o Preço Local tende a cair para o produtor a partir de 33 produtores por rota. Analogamente, pode-se verificar que o Preço Local tende a crescer até o volume de 63.895 litros/mês.

As estimativas das equações (1) e (2) podem ser vistas como alternativas equivalentes. Ou seja, na equação (1), verificam-se os efeitos do volume, do número de produtores e da distância sobre o frete cobrado; na equação (2), medem-se os efeitos das mesmas variáveis sobre o Preço Local, efeitos esses que se dão via efeitos sobre o frete. A diferenciação de preços, em tese, deveria ser totalmente explicada pelas diferenças de fretes; ou seja, numa equação em que a variável dependente fosse o Preço Local e uma das explicativas fosse o frete, então a inclusão do volume entregue pelo produtor como uma segunda variável explicativa não deveria resultar em coeficiente significativo a menos que o volume influenciasse o Preço Local por outras razões que não através do frete. Tal ocorrência, salvo melhor juízo, sugeriria possível discriminação de preços - ou seja, uma diferenciação de preços não devida aos custos de transporte. Veja que se fala apenas em possível discriminação de preços, porque o volume produzido pode estar correlacionado, por exemplo, à qualidade do leite, com o que ele poderia afetar o Preço Local de outra maneira que não através do frete. Se a qualidade do leite dos maiores produtores for superior, a diferenciação de preço não seria necessariamente uma

\footnotetext{
${ }^{7}$ Neste caso, foram incluídas na amostra também aquelas cooperativas para as quais não se dispunha da distância total percorrida em cada rota.
} 
discriminação de preços. Tal discriminação pode aparecer na prática como sendo atribuída ao maior poder de barganha dos maiores produtores, por exemplo.

Essa experiência foi realizada e resultou nas seguintes estimativas:

$$
P L_{i k}=0,39^{*}-1,09^{*} C T_{i k}+4,91 \times 10^{-6^{*}} v_{i}-3,90 \times 10^{-11^{*}} v_{i}^{2}
$$

onde um asterisco representa significância a $1 \%, \mathrm{R}^{2}=0,52$ e $\mathrm{F}=576,4$ significativo a 1\%. Verifica-se ainda que a variável volume - linear e quadrática - apresenta coeficientes significativos, favorecendo a sugestão de discriminação de preços. O valor do teste F para exclusão das duas variáveis envolvendo o volume (nas formas linear e quadrática) é de 451; significativo a 1\%, indicando que as duas variáveis têm um papel de alta relevância na equação acima. Pode-se interpretar, com base nesses resultados, que o produtor recebe um preço básico de $\mathrm{R} \$ 0,39$ (intersecção) do qual se deduz o valor do frete (coeficiente próximo de um). Pode-se verificar ainda que produtores de maiores volumes receberam maiores Preços Locais até o volume de 62,9 mil litros, volume este para o qual o acréscimo de preço chega a $\mathrm{R} \$ 0,15$ por litro. Este seria um efeito sobre o Preço Local em acréscimo àquele associado à redução do frete devido à maior produção entregue.

\subsection{Linhas de coleta}

O presente trabalho coletou informações de 63 linhas de coleta, com volume médio de coleta por linha de 84 mil litros por mês, variando de uma amostra de 3.874 litros a 338.037 litros por mês, conforme pode ser observado na Figura 6. O número de produtores nas linhas varia de 1 a 87 produtores, com uma média de aproximadamente 23 produtores por linha. A linha com o menor volume mensal captou 3.874 litros no mês e contém apenas 5 produtores, a coleta sendo realizada a cada dois dias. O preço médio recebido nessa linha foi de $\mathrm{R}$ \$ 0,3593 , com variação de 3,44\% entre o menor e o maior preço. O frete médio cobrado nessa linha foi de R\$ 0,032/litro. Já a linha com o maior 
volume coletado contém 63 produtores, com um preço médio de R\$ 0,4048/litro, com preços variando de $\mathrm{R} \$ 0,3143$ a $\mathrm{R}$ \$ 0,5382 por litro. O frete médio cobrado foi de R\$ 0,026/litro, variando de cobrança zero a R\$ 0,069/litro.

A variação do volume coletado entre as linhas demonstra a dificuldade que o setor de captação das empresas tem em organizar as linhas, e levantar os custos de coleta. Na amostra estudada a maior linha capta quase 90 vezes mais leite do que a menor linha, o que implica um planejamento logístico totalmente diferente entre os diferentes pontos de coleta, sendo de fundamental importância o estudo e conhecimento profundo das rotas.

Uma das linhas desperta certo interesse pela sua peculiaridade. Capta aproximadamente 45 mil litros por mês, de 48 produtores. O maior produtor da linha entregou 110 litros/dia, o que está próximo da média geral da amostra, que é de 106 litros/dia, o que pode caracterizá-la como uma linha somente de pequenos e médios produtores. No entanto, o preço líquido pago é o mesmo para todos os produtores e um valor bastante elevado R \$ 0,4690/litro, já que a média ponderada dos 1.666 produtores é de R\$ 0,42/litro. O frete também não é cobrado de nenhum produtor. Infelizmente não foi possível levantar informações do tamanho (distância) desta rota, mas uma das possíveis explicações para esse evento é a localização da linha, que pode estar bem próxima à indústria. Outra explicação possível é a linha estar em uma região na qual outras empresas também captam leite, e dessa forma estaria havendo uma competição entre as empresas de captação pelos produtores da região. 


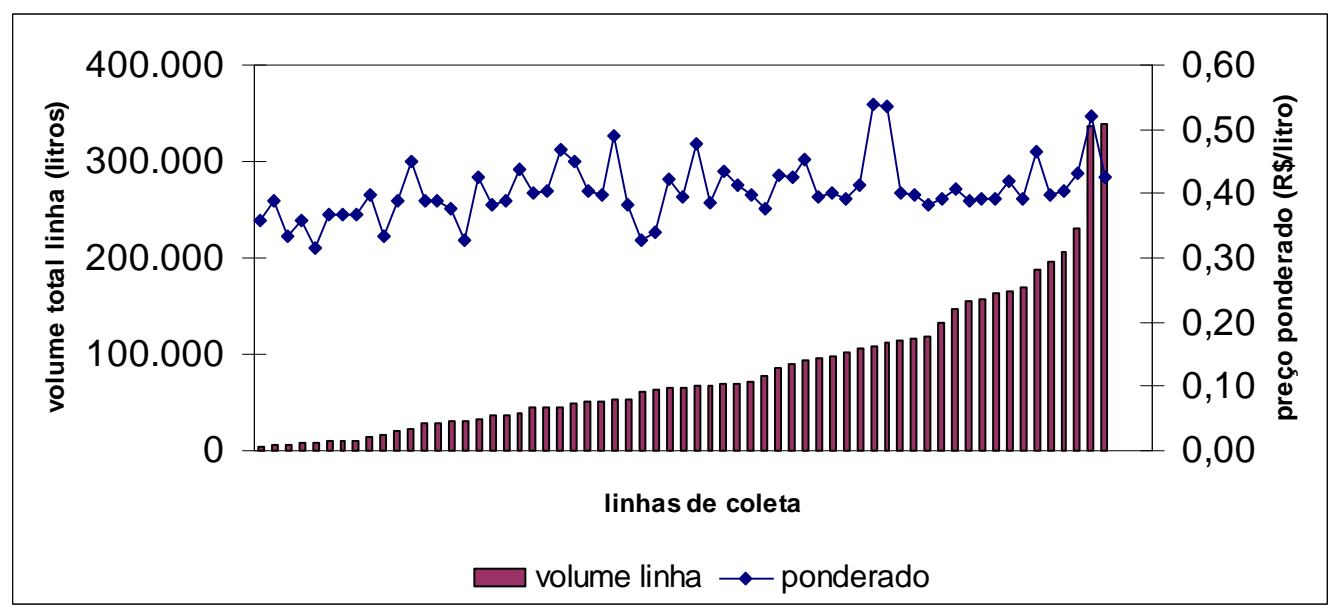

Figura 6 - Volume mensal coletado e preços médios ponderados pagos nas diferentes linhas de coleta

As diferentes linhas têm variações de preços mínimos e máximos oscilando entre zero e mais de $100 \%$ da média, conforme pode ser observado na Tabela 7. A média da variação de preços é de 25\%. A maior variação de preços, aproximadamente $112 \%$ está em uma linha com 11 produtores, que captou 52 mil litros em outubro de 2003, como pode ser observado na Figura 8. O maior produtor entregou 1.000 litros por dia, ou seja, 57\% de todo volume captado na linha, e recebeu R\$ 0,5410/litro, 28 centavos acima do menor preço. A variação de preços possivelmente seja explicada pelo poder de barganha do produtor, que provavelmente viabiliza a rota e não paga frete.

É interessante que um produtor com o mesmo volume mensal, recebe diferentes valores entre as linhas. Por exemplo, a amostra contém 12 produtores que entregam exatamente 1500 litros/mês, todos de linhas de coleta diferentes; no entanto, os valores recebidos entre eles variam entre $\mathrm{R} \$ 0,3415$ a $\mathrm{R} \$ 0,4070$, uma diferença de mais de 6 centavos ou quase 20\%. Dessa forma, o valor médio, ponderado pelo volume, recebido pelos produtores, ou, o custo médio de aquisição do leite pelas empresas varia bastante entre as linhas. Há linhas onde o litro do leite foi adquirido na média a R\$ 
0,3144 e outras, no entanto, a $\mathrm{R} \$ 0,5383$, nesse caso com somente dois produtores que entregaram cada um mais de 3000 litros/dia.

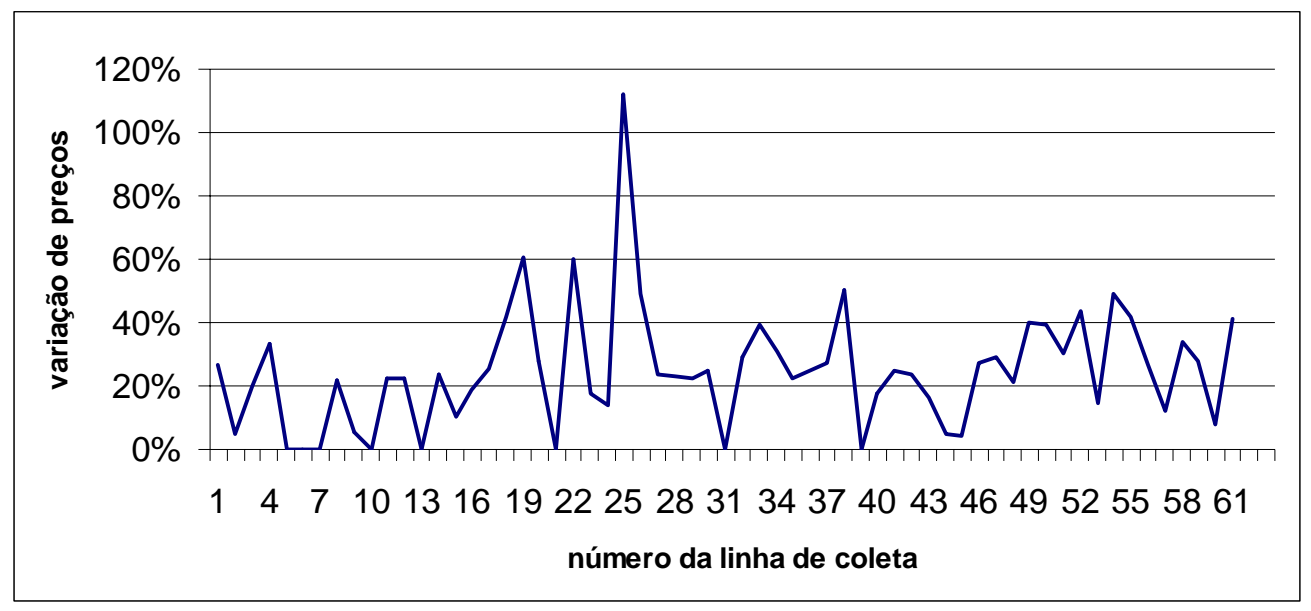

Figura 7 - Variações percentuais entre os preços mínimos e máximos das diferentes linhas de coleta

Foi estimado um modelo para analisar possíveis fatores que estariam influenciando no preço médio líquido pago aos produtores, ponderado pelo volume entregue, de cada linha de coleta. Foi incluída na equação o volume total da linha e o número de produtores para tentar explicar o preço ponderado. A suposição é que à medida que se reduz o volume total da linha e se aumenta o número de produtores na linha, o preço médio decresça, já que o menor volume e o maior numero de produtores na linha estaria indicando um pequeno volume por produtor. 
Tabela 16. Influência do volume total da linha e do número de produtores no preço médio recebido pelos produtores, ponderado pelo volume individual

\begin{tabular}{|c|c|c|c|}
\hline \multicolumn{4}{|l|}{ Variável dependente $=$ PMP } \\
\hline & Variável & Coeficiente & Valor $\mathrm{t}$ \\
\hline Variáveis explicativasConstant & & 0,3993477 & $(35,84)$ \\
\hline & Vol & $8,96 \times 10^{-7}$ & $(4,92)$ \\
\hline & $\mathrm{Vol}^{2}$ & $-1,7 \times 10^{-12}$ & $(-2,99)$ \\
\hline & Nprod & $-0,0027872$ & $(-3,99)$ \\
\hline & Nprod $^{2}$ & 0,0000206 & $(2,28)$ \\
\hline
\end{tabular}

Número de observações $=63 ; \mathrm{R}^{2}=0,4914 ; \mathrm{R}^{2}$ ajustado $=0,7749$

onde:

PMP = Preço Médio (Ponderado pelo volume) por linha em reais

Vol $\quad=$ Volume total da linha coletado no mês, em litros

$\mathrm{Vol}^{2} \quad=$ Quadrado do volume total da linha coletado no mês em litros

Nprod = número de produtores da linha

Nprod $^{2}=$ quadrado do número de produtores

As variáveis incluídas no modelo explicam 49\% das variações no preço ponderado do leite. A estimação da equação sugere que o preço médio ponderado aumenta até um valor máximo de 263.529 litros de leite, reduzindo a partir de então. Com relação ao número de produtores na linha, o preço líquido ponderado na linha decresce até um valor máximo de 68 produtores na linha.

Outras variáveis não incluídas no modelo podem estar ajudando a explicar a diferença de preços médios entre as linhas. Entre essas variáveis não abrangidas, o tipo de pavimentação das linhas de coleta pode influenciar diretamente os custos de coleta. A presença de mais empresas atuando e comprando leite, ou seja, competindo pelos produtores na mesma linha também estaria influenciando as diferenças de preços. 


\section{CONCLUSÕES}

O setor lácteo brasileiro está atravessando um período de profundas mudanças tecnológicas, estruturais (tamanho e distribuição de produtores, cooperativas, indústrias, varejo, etc..), econômicas (liberação dos controles estatais, abertura externa, mudanças macroeconômicas). Tais mudanças afetam tanto o setor primário, como as empresas de captação e transporte, pelas indústrias e atingem o consumidor.

O produtor, além de outras, defrontou-se com alterações nos sistemas de pagamento e cobrança de frete, temas da presente dissertação. Não existe no Brasil uma homogeneidade nos sistemas de pagamento do leite e de cobrança de frete. Em alguns estados (representando cerca de $10 \%$ das cooperativas), considera-se somente a qualidade no sistema de pagamento

A implantação da portaria 56, inicialmente proposta para entrar em vigor em 2000, prorrogada para 2005, exigirá mudanças bastante profundas no setor produtivo e industrial. A questão que deve ser discutida é se o setor já estaria preparado para implementar as novas regras. A amostra estudada demonstra que $60 \%$ dos produtores entregam até 50 litros/dia, e a média geral é de 107 litros/dia, o que é bastante baixo e provavelmente inviabilizaria a implantação de resfriadores na propriedade, devido ao alto custo de aquisição. Seriam necessários aproximadamente 13.000 litros de leite para comprar um resfriador de 300 litros. Daí o setor reivindicar linhas especiais de crédito que possibilitem a produtores e empresas captadoras de leite adquirir tanques de resfriamento individuais ou coletivos, equipamentos e itens de infra-estrutura. 
O volume de leite produzido aparenta ser um dos requisitos básicos para sobrevivência nesse novo cenário, a atividade vem se profissionalizando e se adaptando a novos padrões de produção. No entanto, a fixação de preços norteada apenas pelo volume, agravada pela possibilidade de discriminação de preços baseada nesse mesmo critério, não é a melhor forma de definir quais os produtores que permanecerão na atividade. Pode-se aceitar a eliminação dos produtores menos eficientes e que não apresentam uma capacidade de adaptação e ajustes, porém podem estar sendo excluídos produtores eficientes por causa do baixo volume produzido.

Uma das propostas, além do pagamento por qualidade, seria a de atrelar o pagamento do leite às diferenças do volume entregue na safra e entressafra, ou seja, produtores que apresentam menores variações entre os períodos, receberiam mais.

Quanto aos resultados desta pesquisa, seria recomendável realizar estudos mais abrangentes, incluindo um maior número de cooperativas e empresas privadas, para verificar se o comportamento de fixação de preço se confirma. Se a discriminação de preços está de fato presente, precisa ser melhor estudada e discutida, visando uma melhora conjunta no setor lácteo brasileiro.Cerca de 55\% das cooperativas consultadas incluem qualidade e volume no cálculo do preço ao produtor, mormente nas regiòes com mercado mais amplo territorialmente, onde o frete é determinante na economicidade do sistema como um todo. Em torno de $60 \%$ das cooperativas pesquisadas utilizam o volume captado para estabelecer o valor do frete cobrado. A distância entre a produção da matéria prima e a cooperativa não é levada em consideração pela maioria delas. Uma das tendências do setor é a isenção do pagamento de frete pelos produtores. Este custo seria assumido pelas cooperativas e negociado diretamente com as empresas que fazem a captação, já que este serviço também vem sendo terceirizado.

As constatações efetuadas permitem afirmar que o valor do frete cobrado aos produtores, como se poderia esperar, está vinculado positivamente ao tamanho da rota de coleta e ao número de produtores na rota e negativamente ao volume coletado de cada produtor. Essas mesmas variáveis influem também de acordo com a lógica econômica 
nos preços recebidos pelos produtores. Observou-se, todavia, que o volume produzido influenciava positivamente os preços recebidos também por outras vias que não seu impacto sobre o valor do frete. Essa é, fora de dúvida, uma forte evidência favorável à discriminação de preços contra os menores produtores, embora não seja uma prova cabal da ocorrência de tal fato. Volume pode estar associado à qualidade do produto, por exemplo. Em que pese tal dúvida, permanece a esse respeito grande preocupação, posto que tal possível discriminação de preços estaria sendo praticada por cooperativas. 
ANEXOS 
ANEXO A - Maiores empresas de laticínios do Brasil

\begin{tabular}{|c|c|c|c|c|c|c|c|c|c|c|}
\hline \multicolumn{2}{|r|}{ Empresas/Marcas } & \multicolumn{3}{|c|}{$\begin{array}{l}\text { Recepção anual de leite } \\
\text { (em mil litros) }\end{array}$} & \multicolumn{3}{|c|}{ Número de produtores } & \multicolumn{3}{|c|}{ Litros/dia/produtor } \\
\hline & & 2000 & 2001 & 2002 & 2000 & 2001 & 2002 & 2000 & 2001 & 2002 \\
\hline 1 & NESTLE & 1.393 .000 & 1.425 .628 & 1.489 .029 & 14.142 & 8.536 & 7.192 & 270 & 458 & 567 \\
\hline 2 & PARMALAT & 919.483 & 941.490 & 947.832 & 15.550 & 15.300 & 12.605 & 162 & 169 & 206 \\
\hline 3 & ITAMBÉ & 773.000 & 832.000 & 732.000 & 8.400 & 7.990 & 6.010 & 252 & 285 & 334 \\
\hline 4 & ELEGÊ & 760.239 & 782.141 & 711.335 & 32.188 & 31.282 & 28.665 & 65 & 69 & 68 \\
\hline 5 & CCL & 512.687 & 488.131 & 307.766 & 8.925 & 8.191 & 4.512 & 157 & 163 & 187 \\
\hline 6 & DANONE & 130.210 & 247.487 & 272.236 & 1.420 & 2.452 & 2.470 & 251 & 277 & 302 \\
\hline 7 & SUDCOOP & 181.670 & 209.070 & 230.952 & 4.625 & 6.333 & 6.993 & 108 & 90 & 90 \\
\hline 8 & CENTROLEITE & 174.902 & 220.533 & 213.503 & 4.205 & 4.725 & 4.905 & 114 & 128 & 119 \\
\hline 9 & EMBARÉ & 123.471 & 180.081 & 192.378 & 2.863 & 3.203 & 2.884 & 118 & 154 & 183 \\
\hline 10 & Latic. Morrinhos & 146.200 & 207.031 & 188.241 & 7.292 & 7.299 & 4.990 & 55 & 78 & 103 \\
\hline 11 & LEITE NILZA & 141.449 & 139.937 & 182.568 & 2.615 & 2.384 & 3.031 & 148 & 161 & 165 \\
\hline 12 & BATÁVIA & 272.775 & 225.659 & 165.276 & 7.505 & 6.820 & 6.529 & 100 & 91 & 69 \\
\hline 13 & LIDER & 206.568 & 220.000 & 163.766 & 8.795 & 7.035 & 2.807 & 64 & 86 & 160 \\
\hline 14 & GRUPO VIGOR & 229.629 & 209.743 & 154.158 & 3.693 & 2.039 & 1.525 & 170 & 282 & 277 \\
\hline 15 & ILPISA & 121.455 & 127.830 & 117.637 & 858 & 627 & 729 & 388 & 559 & 442 \\
\hline \multicolumn{2}{|c|}{ TOTAL } & 6.086 .738 & 6.371 .761 & 6.014 .227 & 123.076 & 114.216 & 95.847 & 135 & 153 & 172 \\
\hline
\end{tabular}

Fonte: Leite Brasil (2004) e EMBRAPA (2004) 
ANEXO B - Brasil: produção, importação e consumo de leite

\begin{tabular}{|c|c|c|c|c|c|c|c|c|}
\hline Ano & $\begin{array}{c}\text { Produção } \\
\text { (milhões } \\
\text { litros) }\end{array}$ & $\begin{array}{l}\text { Var. } \\
\text { (\%) }\end{array}$ & $\begin{array}{c}\text { Importação } \\
\text { (milhões } \\
\text { litros) }\end{array}$ & $\begin{array}{l}\text { Var. } \\
\text { (\%) }\end{array}$ & $\begin{array}{c}\text { Exportação } \\
\text { (milhões } \\
\text { litros) }\end{array}$ & $\begin{array}{l}\text { Var. } \\
\text { (\%) }\end{array}$ & $\begin{array}{c}\text { Consumo } \\
\text { Per capita } \\
\text { aparente }\end{array}$ & $\begin{array}{l}\text { Var. } \\
\text { (\%) }\end{array}$ \\
\hline 1980 & 11.162 & - & 774 & - & & & 100,7 & - \\
\hline 1981 & 11.324 & 1,45 & 56 & $-92,75$ & & & 93,9 & $-6,74$ \\
\hline 1982 & 11.461 & 1,21 & 79 & 41,35 & & & 93,2 & $-0,78$ \\
\hline 1983 & 11.463 & 1,02 & 193 & 143,13 & & & 92,1 & $-1,14$ \\
\hline 1984 & 11.933 & 4,10 & 207 & 7,31 & & & 93,9 & 1,98 \\
\hline 1985 & 12.078 & 1,22 & 331 & 59,98 & & & 94,0 & 0,12 \\
\hline 1986 & 12.492 & 3,43 & 2.319 & 600,60 & & & 110,0 & 16,99 \\
\hline 1987 & 12.996 & 4,03 & 813 & $-64,94$ & & & 100,6 & $-8,54$ \\
\hline 1988 & 13.522 & 4,05 & 214 & $-73,68$ & & & 98,2 & $-2,34$ \\
\hline 1989 & 14.095 & 4,24 & 1.357 & 534,11 & & & 108,6 & 10,53 \\
\hline 1990 & 14.484 & 2,76 & 906 & $-33,24$ & & & 106,3 & $-2,06$ \\
\hline 1991 & 15.079 & 4,11 & 1.313 & 44,92 & & & 111,6 & 4,99 \\
\hline 1992 & 15.784 & 4,68 & 276 & $-78,98$ & & & 107,6 & $-3,61$ \\
\hline 1993 & 15.591 & $-1,22$ & 632 & 128,99 & & & 107,0 & $-0,54$ \\
\hline 1994 & 15.784 & 1,24 & 1.250 & 97,78 & & & 110,8 & 3,53 \\
\hline 1995 & 16.474 & 4,37 & 3.200 & 156,00 & & & 126,3 & 13,94 \\
\hline 1996 & 18.515 & 12,39 & 2.450 & $-23,44$ & & & 133,5 & 5,72 \\
\hline 1997 & 18.666 & 0,82 & 1.930 & $-21,22$ & & & 129,0 & $-3,34$ \\
\hline 1998 & 18.694 & 0,15 & 2.270 & 17,62 & & & 129,6 & 0,43 \\
\hline 1999 & 19.070 & 2,01 & 2.410 & 6,17 & & & 131,0 & 1,11 \\
\hline 2000 & 19.767 & 3,65 & 1.800 & $-25,31$ & 32,99 & - & 126,8 & $-3,20$ \\
\hline 2001 & 20.510 & 3,76 & 808 & $-55,11$ & 105,74 & 220,6 & 123,1 & $-2,97$ \\
\hline 2002 & 20.400 & $-0,54$ & 1.468 & 81,68 & 184,80 & 74,8 & 124,2 & 0,91 \\
\hline 2003 & 21.300 & 4,41 & 628 & $-57,22$ & 250,00 & 35,3 & 122,6 & $-1,29$ \\
\hline
\end{tabular}

Fonte: Leite Brasil (2004)

* Estimativa (**) em equivalente litros de leite 
ANEXO C - Modelo de questionário

Cooperativa/Empresa:...............................................................................................

Possui pagamento por qualidade? Sim Não

Pagamento por volume? Sim Não

Captação? ........................ (diária/mensal) Número de linhas de coleta de leite?

Número de produtores de leite?

Como é calculado o frete ao produtor? Baseado em: Volume Distancia 


\section{REFERÊNCIAS BIBLIOGRÁFICAS}

ASSOCIAÇÃO BRASILEIRA DE LEITE LONGA VIDA (ABLV). Comportamento das vendas externas de leite “Longa Vida”. http://www.ablv.org.br (01 out. 2003)

BANDEIRA, A. Melhoria da qualidade e a modernização da pecuária leiteira nacional. In: GOMES, S. (Ed.) et al. O agronegócio do leite no Brasil. Juiz de Fora: EMBRAPA, CNPGL, 2001, p.89-100.

BARROS, G.S.C.; GALAN, V.B.; GUIMARÃES, V.A.; BACCHI, M.R.P. Sistema agroindustrial do leite no Brasil. Brasilia: EMBRAPA, 2000, 170p.

BARROS, G.S.C. Economia da comercialização agrícola. Piracicaba: ESALQ, 1985. 240p.

BRANDÃO, A.S.P. Aspectos econômicos e institucionais da produção de leite no Brasil. In: VILELA, D. (Ed.) et al. Cadeia de lácteos no Brasil: restrições ao seu desenvolvimento. Juiz de Fora: EMBRAPA, CNPGL, 2001. p.39-72.

BREDA, L.B. Coordenação da cadeia produtiva do leite: um estudo de subsistemas no oeste de Santa Catarina. Lavras, 2001. 174p. Dissertação (M.S.) - Universidade Federal de Lavras.

BRESSLER, R.G.; KING, R.A. Markets, prices, and international trade. New York: John Wiley \& Sons Inc., 1970. 426p.

CAIXETA FILHO, J.V. Transformações recentes na logística de coleta do leite no Brasil. Preços Agrícolas, v.6, n.74, p.66-69, jan. 2002. 
COOPERATIVA FONTERRA. New Zealand's multinational dairy company. http://www.fonterra.com (05 Aug. 2003)

DORNELAS, S. A coleta a granel de leite refrigerado e suas implicações sobre as relações contratuais entre produtor e indústria: um estudo de caso. Piracicaba, 2000. 128p. Dissertação (M.S.) - Escola Superior de Agricultura "Luiz de Queiroz", Universidade de São Paulo.

EMPRESA BRASILEIRA DE PESQUISA AGROPECUÁRIA (EMBRAPA). Estatísticas do leite. http//www.cnpgl.embrapa.br (20 abr. 2004)

FAO. Food and Agricultural Organization of the United Nacion. http://faostat.fao.org/faostat (25 mar. 2004)

FRANKS, J.R. Recent changes in milk marketing in the UK: farmers's perspective. http://www.ifma.nl/files/papersandposters/PDF/Papers/Franks.pdf (20 Sep. 2004)

GALAN, V.B. Formas de governança e o cooperativismo do leite no Brasil: uma análise do setor, de casos escolhidos e de incentivos. São Paulo, 2000. 144p. Dissertação (M.S.) - Faculdade de Administração e Economia, Universidade de São Paulo.

INSTITUTO BRASILEIRO DE GEOGRAFIA E ESTATÍSTICA (IBGE). Pesquisa pecuária municipal: 2002. http://www.sidra.ibge.gov.br (27 out. 2003)

LEITE BRASIL. Associação Brasileira Dos Produtores De Leite. Estatísticas. http://www.leitebrasil.org.br (20 abr. 2004)

MARTINS, P.C. Políticas públicas e mercados deprimem o resultado do sistema agroindustrial do Leite. Piracicaba, 2003. 217p. Tese (Doutorado) - Escola Superior de Agricultura “Luiz de Queiroz”, Universidade de São Paulo. 
MESQUITA, V. Os pequenos produtores face às transformações no agronegócio do leite em Minas Gerais: estudo de caso. Lavras, 2002. 144p. Dissertação (M.S.) Universidade Federal de Lavras.

PENNINGS, J.M.E.; MEULENBERG, M.T.G. New futures markets in agricultural production rights: possibilities and constraints for the British and Dutch milk quotas markets. Journal of Agricultural Economics, v.49, n.11, p.50-56, 1998.

PRIMO, W.M. Restrições ao desenvolvimento da indústria brasileira de laticínio. In: VILELA, D. (Ed.) et al. Cadeia de lácteos nNo Brasil: restrições ao seu desenvolvimento. Juiz de Fora: EMBRAPA, CNPGL, 2001, p.73-131.

SILVA, I.C.V. Custos e otimização de rotas no transporte de leite a latão e a granel: um estudo de caso. Lavras, 1999. 72p. Dissertação (M.S.) - Universidade Federal de Lavras.

SOARES, M.G.; DEE, T.M.; CAIXETA FILHO, J.V. Logística da coleta de leite na Inglaterra: oportunidades para reduções de custos. Preços Agrícolas, v.11, n.131, p.11-15, set.1997.

STIGLER, G.J. The theory of price. New York: The Macmillan Company, 1946. 340p.

TESTA, V.M.; MELLO, M.A.; FERRARI, D.L.; SILVESTRO, M.L.; DORIGON, C. Impactos do sistema de preços e custos de coleta de leite na exclusão de agricultores familiares (compact disc). In: CONGRESSO BRASILEIRO DE ECONOMIA E SOCIOLOGIA RURAL, 41., Juiz de Fora, 2003. Anais. Brasília: SOBER, 2003.

WHITE, J.; HODGSON, J. New Zealand, pasture and crop science. Auckland: Oxford University Press, 2000. 323p. 